NBER WORKING PAPER SERIES

\title{
AGREEING NOW TO AGREE LATER: \\ CONTRACTS THAT RULE OUT BUT DO NOT RULE IN
}

\author{
Oliver Hart \\ John Moore \\ Working Paper 10397 \\ http://www.nber.org/papers/w10397 \\ NATIONAL BUREAU OF ECONOMIC RESEARCH \\ 1050 Massachusetts Avenue \\ Cambridge, MA 02138 \\ March 2004
}

We would like to thank Bengt Holmstrom, Jozsef Sakovics, and Jonathan Thomas for helpful conversations. We acknowledge financial support from the U.S. National Science Foundation through the National Bureau of Economic Research; the Leverhulme Trust; and the U.K. Economic and Social Research Council. This paper was written while the first author was on sabbatical at the London School of Economics; he would like to thank that institution for its hospitality. The views expressed herein are those of the author and not necessarily those of the National Bureau of Economic Research.

(C)2004 by Oliver Hart and John Moore. All rights reserved. Short sections of text, not to exceed two paragraphs, may be quoted without explicit permission provided that full credit, including (C) notice, is given to the source. 
Agreeing Now to Agree Later: Contracts that Rule Out but do not Rule In

Oliver Hart and John Moore

NBER Working Paper No. 10397

March 2004

JEL No. D8, D23, K12, L22

\section{ABSTRACT}

We view a contract as a list of outcomes. Ex ante, the parties commit not to consider outcomes not on the list, i.e., these are "ruled out". Ex post, they freely bargain over outcomes on the list, i.e., the contract specifies no mechanism to structure their choice; in this sense outcomes on the list are not "ruled in". A "loose" contract (long list) maximizes flexibility but may interfere with ex ante investment incentives. When these incentives are important enough, the parties may write a "tight" contract (short list), even though this leads to ex post inefficiency.

Oliver Hart

Department of Economics

Littauer Center 220

Harvard University

Cambridge, MA 02138

and NBER

oliver_hart@harvard.edu

John Moore

Department of Economics

University of Edinburgh

Edinburgh EH8 9JY

United Kingdom 


\section{Introduction}

An interesting class of contracts has the following form. The parties agree some things now and agree to agree other things later. For example, suppose that an impresario and a pianist sign a contract for a concert, or series of concerts, a year hence. They may decide now on the fee and the broad outlines of the musical program, but may agree that the exact pieces played will be determined later. Or suppose that a printer and a paper manufacturer sign a contract for the delivery of paper. They may decide on the price for the first year, but agree that the price in future years will be subject to negotiation, within limits.

This paper is concerned with contracts of this type. ${ }^{1}$ In order to analyze them, we adopt the following view. We imagine that when parties draw up a contract they specify a list of all the possible outcomes from their transaction (here an outcome is a complete description of what might happen, e.g., a price-quantity-quality vector).

Trade is voluntary and so "no trade" is always on the list. The parties commit not to consider outcomes not on the list; that is, any outcome not on the list is ruled out. In contrast, any outcome on the list may be chosen. However, no mechanism is provided for selecting an outcome from the list; rather the choice will be made through unstructured negotiation or bargaining. In this sense outcomes on the list are not ruled in.

At one extreme the list might consist of a small number of outcomes, e.g., just one (in addition to "no trade"). This corresponds to a very tight contract since there is little or nothing to bargain over later. At the other extreme the list might be very long.

\footnotetext{
${ }^{1}$ Lawyers refer to such contracts as indefinite agreements, or agreements with open terms, or agreements to agree. See Farnsworth (1999, p.110, pp.207-216, and particularly pp. 217-222). Two recent contributions to the legal literature are Ben-Shahar (2004) and Scott (2003). A key issue for these authors, and for the courts, is whether an agreement is too indefinite to be enforceable. Legal enforceability is not central to our analysis, and so the attitudes of the courts to indefinite agreements, and their role in filling in the gaps in these agreements, are not major issues in our paper.
} 
This corresponds to a loose contract since there is much to bargain over later. Note that "no contract" fits easily into this framework. "No contract" corresponds to the list of all possible outcomes; the reason is that if the parties write no contract now, then nothing is ruled out since they can always contract later.

We are interested in how long the parties' list should be. The trade-off is the following. The advantage of a long list is flexibility: the parties are more likely to be able to choose an outcome that fits their circumstances. That is, ex post, the parties have more scope to locate where they want to be in outcome space. However, this very flexibility has its disadvantages. A long list opens the door to bargaining. As a result, from an ex ante perspective, the parties may end up where they don't want to be.

We study the optimal contract in light of this trade-off. We show that, if relationship-specific investments are large, the parties may need to choose a tight contract, e.g., in the music example, the contract might specify that the pianist will play Bach's 24 Preludes and Fugues for a fixed fee in all circumstances, even though this is not always ex post efficient -- it is sometimes more efficient to play Shostakovich's 24 Preludes and Fugues. The parties may also make a "middle-of-theroad" choice: they might agree that Mozart will always be performed, even though this is never efficient, because it is a reasonable compromise between the efficient choices of Bach and Shostakovich. On the other hand, if relationship-specific investments are not large, the parties will choose a loose contract: the contract will fix the pianist's fee but leave the choice of music to be decided later. Finally, the parties may choose a convex combination of the above contracts, which can be given a temporal interpretation: the parties agree that the pianist will play Bach in some 
performances in the concert series, and the music will be left open for the remaining performances.

The overarching idea behind our analysis is that a contract guarantees what will not happen, but not what will happen. That is, in writing an ex ante contract, the parties restrict the set of outcomes over which they are free to bargain ex post: they tie their hands (not always a good idea for a pianist). In particular, by fixing the price, they deliberately rule out the kinds of side payments necessary for the Coase theorem to work. ${ }^{2}$ This is the source of what is perhaps our most important finding: equilibrium outcomes can be ex post inefficient even though information is symmetric.

Our model not only suggests that the parties will fix or restrict some variables, but it also has implications about which variables the parties should pin down and which they should leave open. We show that, if the parties know that some aspect of the outcome -- the price or nature of the music, say -- should be in a particular range, the contract should say this. To put it another way, looseness is desirable only to the extent that there is genuine uncertainty about what should happen. However, there is an asymmetry between quality and price. In a rough sense it is more important for the parties to specify price than quality because their interests over the former are diametrically opposed, whereas efficiency considerations will lead to some congruence of preferences over the latter. ${ }^{3}$

\footnotetext{
${ }^{2}$ Harstad (2003) presents a model of regional coordination and negotiation in which it is sometimes efficient, ex ante, to limit side payments.

${ }^{3}$ Ours is, of course, not the only explanation of why parties choose to leave some variables open in a contract. To mention some other theories: it has been argued that a loose or open contract can be desirable for signalling reasons (see Allen-Gale (1992), Spier (1992)); to encourage reputation-building and trust (see Baker et al. (1994), Boot et al. (1993), MacLeod-Malcomson (1989)); and to allow parties to punish "off the equilibrium path" behaviour (see Bernheim-Whinston (1998)). Scott (2003) and Ben-Shahar (2004) have recently used these and related theories to understand why parties write agreements to agree. Scott (2003) argues that reciprocal fairness can explain this phenomenon; while Ben-Shahar (2004) suggests that, among other things, agreements to agree are a way for parties, ex ante, to overcome negotiation deadlocks when they have different priors.
} 
Our assumption that a contract rules out (outcomes not on the list), but does not rule in (outcomes on the list) is strong. In Section 4 we provide some foundations for this assumption. We show that it follows from two more primitive assumptions. The first, to which we have already alluded, is that trade is voluntary, by which we mean that, irrespective of any long-run promises entered into ex ante, each party can unilaterally prevent trade ex post by "refusing to cooperate"; moreover, it is impossible for an outsider to verify which party was responsible. The second is that the parties can engage in various forms of commitment: specifically, they can make long-run commitments not to renegotiate their contract; and they can make short-run commitments either to trade or not to trade.

It is useful to provide a simple example that illustrates the model's trade-offs. Suppose that a buyer needs one unit of homogeneous input from a seller at some future date 1, but at date 0 the seller's costs are uncertain. (The model in the body of the paper focuses instead on the richer case where the nature of the good -- e.g., the type of music to perform -- is uncertain.) In particular, imagine that the value of the input to the buyer is 20 and the seller's cost $\mathrm{c}$ is 10 with probability $1 / 2$ and 16 with probability $1 / 2$. The parties are risk neutral and the seller's cost will be observed by both parties at date 1 ; however, $\mathrm{c}$ is not verifiable. In addition the buyer must make a relationship-specific investment at cost $i$, between dates 0 and 1 , in order to realize the value $20 .^{4}$

Recall that a contract is a list of outcomes -- in this case, price-quantity $(\mathrm{p}, \mathrm{q})$ pairs. Recall also that we suppose that trade is voluntary. Normalize so that if no trade occurs the buyer pays the seller nothing.

\footnotetext{
${ }^{4}$ Thus there is a potential hold-up problem. See, e.g., Grout (1984), Klein et al. (1978), Williamson (1975)
} 
A good contract in this setting is one that specifies an input price high enough to encourage the seller to supply but low enough that the buyer has an incentive to invest. Two contracts stand out. One is a "fixed-price" or tight contract that sets the input price equal to 10 , i.e., the contract is $\{p=10, q=1\}$. The other is a "flexibleprice" or loose contract that allows the price to be 10 or 16 . We assume that, if the price can be 10 or 16, it can also be anything in between, since the parties can always bargain to intermediate prices by randomization (in fact, we assume that they cannot commit, ex ante, not to randomize ex post). Thus the second contract is $\{10 \leq \mathrm{p} \leq 16, \mathrm{q}=1\}$

With the tight contract, trade will take place if and only if $\mathrm{c}=10$. The reason is that, when $\mathrm{c}=10$, trade is individually rational and there is nothing to bargain over. In contrast, when $\mathrm{c}=16$, trade will not occur since trade is not individually rational for the seller. Moreover, by assumption, the parties stick to their list of outcomes, i.e., no renegotiation takes place on price.

With the flexible price or loose contract, trade will occur always since price can vary with cost. If $c=16$, there is nothing to bargain over: $p=16$. If $c=10$, there is something to bargain over since any price between 10 and 16 is individually rational for both parties. We adopt the symmetric Nash bargaining solution (with no trade as the disagreement point). In the current context this means that $\mathrm{p}=15$ when $\mathrm{c}=10$. In summary, the loose contract yields $\mathrm{p}=15$ when $\mathrm{c}=10$ and $\mathrm{p}=16$ when $\mathrm{c}=16$.

The tight contract delivers an expected gross payoff to the buyer of 5 (the buyer gets 10 with probability $1 / 2$ ), and an expected gross surplus of the same amount. The loose contract delivers an expected gross payoff to the buyer of $4 \frac{1}{2}$, and an expected gross surplus equal to 7 . 
Comparing the two contracts, we see that the loose contract dominates the tight contract in terms of gross surplus -- in fact, it achieves the first-best -- but the tight contract yields a higher return for the buyer. The conclusion is that, if $i \leq 4 \frac{1}{2}$, the loose contract is optimal and achieves the first-best. However, if $4 \frac{1}{2}<\mathrm{i} \leq 5$, the loose contract is infeasible and the tight contract will be used. (If $\mathrm{i}>5$, the project will be abandoned; note that, in the first-best, the project would be abandoned only if i > 7.) In fact, in this case, the optimum is a convex combination of the tight contract and the loose contract: one interpretation of this convex combination is that there is a flow of trade in the "date 1 period" (akin to a series of concerts, rather than just a single concert), and that the tight contract will be used for a fraction $\tau$ of date 1 , and the loose contract for the remaining fraction $(1-\tau)$, where $\tau 5+(1-\tau) 9 / 2=\mathrm{i}$.

We see from this example that, as the investment cost rises, there is a progression from a loose contract to a tight contract to the project being abandoned. In Section 3, we show that this progression occurs generally; however in some cases the region where the tight contract is optimal disappears (this happens because the tight contract can be sufficiently inefficient ex post that it is actually worse than the loose contract for ex ante incentives).

We can tease out one further implication from this example. Suppose that the seller's costs are distributed on the whole interval $[10,20]$ rather than just being 10 or 16. Under these conditions what corresponds to the loose contract is the contract $\{10 \leq \mathrm{p} \leq 20, \mathrm{q}=1\}$. As in the two-state example, it will sometimes be optimal to use this contract for a fraction of the date 1 period. But this contract is equivalent to no contract at all, since price can never rise above 20 or fall below 10 on account of individual rationality. Thus we can interpret the model as saying that the parties will 
choose a contract of limited duration, i.e., they will choose one contract for part of their relationship and no contract for the rest.

We should compare our approach with others in the literature. Our view, that contracts rule out but do not rule in, differs in at least one dimension. In the ArrowDebreu model, the states of the world and all the choice variables are observable and verifiable, and parties write a contract specifying exactly what will happen in every state. Such a contract "rules out" (since nothing outside the contract can ever occur) and "rules in" (since there is no ambiguity about what will be chosen within the contract in any eventuality). Mechanism design theory extends the Arrow-Debreu model to allow for less than full information about the state of the world. In the classical mechanism design framework, it is supposed that parties write a contract that can never be renegotiated and that provides a mechanism for determining ex post outcomes. For example, if there is asymmetric information between the contracting parties, the mechanism may specify that the informed party chooses an outcome from a prescribed menu, e.g., of price-quantity or price-quality pairs. ${ }^{5}$ If there is two-sided asymmetric information, both parties may be required to participate in the mechanism. ${ }^{6}$ Alternatively, the state may be "observable but not verifiable", in that it cannot be verified by outsiders (the planner, the courts), even though it is observed by both of the inside parties: again, a mechanism will typically involve the participation of both parties. ${ }^{7}$ In all these cases, the contract "rules out" ( since nothing outside the contract is possible); and "rules in", in the sense that a mechanism for determining the outcome within the contract is provided ${ }^{8}$.

\footnotetext{
${ }^{5}$ See, e.g., Mirrlees (1971), Mussa-Rosen (1978).

${ }^{6}$ See, e.g., Myerson (1979), Myerson-Satterthwaite (1983).

${ }^{7}$ See, e.g., Maskin (1999), Moore-Repullo (1988).

${ }^{8}$ The large law and economics literature on contracts is also mainly concerned with situations where contracts rule out and rule in. (However, some of the literature covers as well the case where contracts do not rule out but do rule in.) See, e.g., Shavell (2004).
} 
A more recent branch of the mechanism design literature allows for renegotiation. Here, contracts do not "rule out", since renegotiation introduces choices not mentioned in the initial contract. However, contracts do "rule in", given that a mechanism for determining an outcome within the initial contract is provided: e.g., under asymmetric information one party has the right to choose from a menu (but the possibility of renegotiation will reduce the value of this right). ${ }^{9}$ Renegotiation under observable but not verifiable information can drastically reduce the power of contractually-specified mechanisms. ${ }^{10}$ This latter paradigm has been used as a basis for thinking about incomplete contracts. ${ }^{11}$

To repeat, we assume that agents can commit not to renegotiate: our contracts do "rule out". In this respect our approach is quite classical. Our main innovation is to suppose that contracts do not "rule in": outcomes mentioned in a contract are haggled over -- there is unstructured bargaining -- rather than being determined according to a contractually-specified mechanism. (There is a fourth entry in our "ruling-in-or-out" taxonomy: contracts that neither rule out nor rule in. Such contracts impose no constraints whatsoever on what can happen and so are worthless.) $)^{12}$

The paper is organized as follows. The model is laid out in Section 2.

Section 3 contains the analysis of an optimal contract. Section 4 provides some justifications for restricting attention to our class of contracts. Finally, Section 5 discusses some extensions and directions for future research.

\footnotetext{
${ }^{9}$ For renegotiation under asymmetric information between the contracting parties, see, e.g., Dewatripont (1989), Hart-Tirole (1988), Laffont-Tirole (1990).

${ }^{10}$ See, e.g., Che-Hausch (1999), Hart-Moore (1999), Maskin-Moore (1999), Reiche (2003), Segal (1999), Segal-Whinston (2002).

${ }^{11}$ See, e.g., Aghion et al. (1994), Chung (1991), Hart-Moore (1988), MacLeod-Malcomson(1993), Noldeke-Schmidt (1992), Rogerson (1992).

${ }^{12}$ This (excessively brief) discussion of the mechanism design literature has been restricted to situations of hidden information, where there is less than full information about the state of the world. There is, of course, a huge literature on hidden actions, where certain choice variables (like effort) are not observable (or verifiable); see, e.g., Holmstrom (1979), Mirrlees (1999).
} 


\section{The Model}

We consider the relationship between a risk neutral buyer and a risk neutral seller lasting from date 0 to date 1 . The buyer wants a service from the seller ex post, at date 1 . To fix ideas, we will use the concert example described in the Introduction. That is, we suppose that the buyer is an impresario arranging a concert and the seller is a pianist. (For some interpretations of the model, it will be more appropriate to think of the pianist as performing a series of concerts rather than just one.) The ideal nature of the seller's service -- that is, the musical program -- is unclear when the parties write their contract ex ante, at date 0 : it will depend on what transpires between dates 0 and 1 . We assume that, for a successful concert to occur, the buyer must make a relationship-specific investment, e.g., he must promote the concert (the investment is observed only by the buyer). The seller has no investment. For clarity of exposition we suppose that, ex ante, the seller gets all the surplus from the transaction (e.g., because there are many potential buyers at date 0$).{ }^{13}$ The time-line is as in Figure 1.

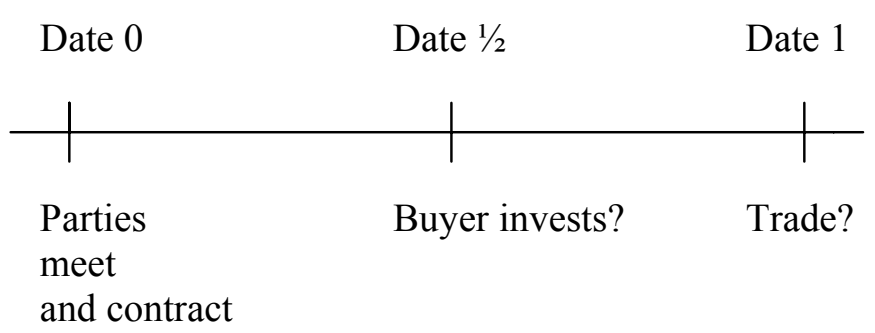

Figure 1

\footnotetext{
${ }^{13}$ All our characterization results extend to any other ex ante division of surplus, modulo some transfer payment at date 0 .
} 
We shall suppose that the possible musical programs can be represented by points $\lambda$ on the interval $[0,1]$. For convenience, we will identify a musical program with a composer. Three musical programs or composers will have particular significance: $\lambda=0, \lambda=1 / 2$, and $\lambda=1$. We will refer to these composers as Bach, Mozart, and Shostakovich, respectively.

For simplicity, we suppose that at date 1 there are just two possible states of the world, 0 and 1 , with probabilities $\pi_{0}$ and $\pi_{1}=1-\pi_{0}$, respectively, where $0<\pi_{0}<1$. Without loss of generality, we take $\pi_{0} \geq 1 / 2$. Assume first that the buyer has invested. Then in state 0 the value (enjoyed by the buyer) and the cost (borne by the seller) of the music $\lambda$ are given by

$$
\mathrm{v}_{0}(\lambda)=\mathrm{v}-\lambda \Delta, \quad \mathrm{c}_{0}(\lambda)=\mathrm{c}-\lambda \delta
$$

respectively, where $\Delta>0, \delta>0$. That is, Bach is the highest value and highest cost composer in state 0 (with value v and cost c); and value and cost decline linearly as we move towards Shostakovich. We assume that $\Delta>\delta$, i.e., value declines by more than cost; and that $\mathrm{v}-\Delta>\mathrm{c}-\delta>0$, i.e., there are gains from trade even from Shostakovich.

The assumption $\Delta>\delta$ implies that Bach is the efficient choice in state 0 . The case $\Delta \leq \delta$ is also potentially of interest, but we will see in Section 3 that the first-best is easy to achieve under these conditions.

In state 1 , the interval $[0,1]$ is rotated 180 degrees in the sense that value and cost are given by

$$
\mathrm{v}_{1}(\lambda)=\mathrm{v}-(1-\lambda) \Delta, \quad \mathrm{c}_{1}(\lambda)=\mathrm{c}-(1-\lambda) \delta
$$

That is, Shostakovich is efficient in state 1 , with value and cost declining linearly as we move towards Bach. The one composer whose value and cost are the same in the two states is Mozart. 
We will make the further assumption that the total variation in the value and cost of performance, $\Delta+\delta$, is not too large; specifically,

(A.1) $\mathrm{v}-\mathrm{c}>\Delta+\delta$.

The reason for (A.1) will become clear in Section 3, Lemma 1.

The above is for the case where the buyer invests. If the buyer does not invest, we suppose that the value of the concert is zero, i.e., there are no gains from trade ex post.

In a first-best world, the efficient music would be selected in each state.

Suppose the investment costs i. We ignore discounting, so, if investment occurs, the net present value of the transaction is $\mathrm{v}-\mathrm{c}-\mathrm{i}$, which we assume is strictly positive.

It will be useful to have a running numerical example. Suppose $\mathrm{v}=20$, $\mathrm{c}=10, \Delta=6, \delta=2$. Then in state 0 , Bach has value 20 and cost 10 , while Shostakovich has value 14 and cost 8 . In state 1 , Shostakovich has value 20 and cost 10, while Bach has value 14 and cost 8 . In both states, Mozart has value 17 and cost 9. The first-best net present value of the project is $10-\mathrm{i}>0$.

If the state of the world is verifiable, the first-best is easy to achieve. The buyer and seller can write a contract specifying that the seller plays Bach in state 0 and Shostakovich in state 1 , each at a price of $\mathrm{c}$. The buyer then receives the full gains from trade, $\mathrm{v}-\mathrm{c}-\mathrm{i}$, and has socially correct investment incentives. (The buyer will make an upfront transfer $\mathrm{v}-\mathrm{c}-\mathrm{i}$ to reallocate the surplus to the seller.) From now on we suppose that, even though each party observes the state of the world and the other party's payoff (in effect, the seller can deduce whether the buyer has invested), none of these variables is verifiable.

As emphasized in the Introduction, we are interested in a situation where contracts "rule out" but do not "rule in". Specifically, we assume that at date 0 the 
parties write a contract consisting of a list of outcomes -- in the current context, $(\lambda, p)$ pairs, together with "no trade". Anything not on the list is ruled out. However, neither party can be forced to accept anything on the list except for no trade. That is, the parties bargain over outcomes on the list, where the disagreement point is no trade. Without loss of generality, we normalize the no trade price to be zero.

In Section 4, we will provide some justifications for restricting attention to this class of contracts. To give a flavour of the argument, consider a classic "ruling-in" contract, where the buyer is given the right to choose any composer at a price of c. If ex post bargaining can be avoided, this contract delivers first-best since the buyer will choose the composer with value v, which happens to be the efficient outcome. In our view, the problem with this contract is that the seller can threaten not to trade unless the buyer chooses the composer the seller wants. We postpone further discussion of these matters until Section 4, and for the moment simply take our class of contracts as given.

We will take the view that the parties bargain according to the symmetric Nash bargaining solution. ${ }^{14}$ Let $\mathrm{C}$ be the set of $(\lambda, p)$ pairs specified in the contract, together with "no trade". We assume that the parties can convexify $\mathrm{C}$ by choosing lotteries over the outcomes as part of the bargaining: indeed, they cannot commit at date $0 \underline{\text { not }}$ to randomize at date 1 . Thus we extend $\mathrm{C}$ to its convex hull $\overline{\mathrm{C}}$. Given that each party can unilaterally select no trade, in each state of the world the parties will bargain over the subset of elements in $\overline{\mathrm{C}}$ that are individually rational, i.e., that yield non-negative payoffs. Let $\left(\lambda_{0}, \mathrm{p}_{0}\right)$ be the outcome of Nash bargaining in state 0 and $\left(\lambda_{1}, \mathrm{p}_{1}\right)$ the outcome in state 1. (In principle, no trade could be the outcome in one of the states. We consider and rule this out in the next section.)

\footnotetext{
${ }^{14}$ See Nash (1950). For discussions, see Binmore et al. (1986) and Roth (1979).
} 
A further simplification is possible. The Nash bargaining solution possesses the property of independence of irrelevant alternatives. Thus the outcomes $\left(\lambda_{0}, \mathrm{p}_{0}\right)$, $\left(\lambda_{1}, p_{1}\right)$ will still emerge from the bargaining if we replace the original contract by a new contract consisting just of the pairs $\left(\lambda_{0}, \mathrm{p}_{0}\right),\left(\lambda_{1}, \mathrm{p}_{1}\right)$. Of course, we have to make sure that this contract is "group incentive compatible". By this we mean that $\left(\lambda_{\mathrm{j}}, \mathrm{p}_{\mathrm{j}}\right)$ does emerge from the bargaining in state $\mathrm{j}, \mathrm{j}=0,1$ : given that the parties can convexify by randomization, $\left(\lambda_{\mathrm{j}}, \mathrm{p}_{\mathrm{j}}\right)$ must be the Nash bargaining solution in state $\mathrm{j}$ when all the points on the line segment joining $\left(\lambda_{0}, \mathrm{p}_{0}\right)$ and $\left(\lambda_{1}, \mathrm{p}_{1}\right)$ are available. We study the incentive-compatibility constraints in the next section.

\section{Analyzing the Optimal Contract}

In this section we study the nature of an optimal contract. We begin, however, by making some observations about feasibility.

By construction, $\left(\lambda_{0}, \mathrm{p}_{0}\right)$ is the Nash bargaining outcome in state 0 and $\left(\lambda_{1}, \mathrm{p}_{1}\right)$ is the Nash bargaining outcome in state 1. This fact has two implications. First, $\left(\lambda_{\mathrm{j}}, \mathrm{p}_{\mathrm{j}}\right)$ must give each party a non-negative payoff in state $\mathrm{j}, \mathrm{j}=0,1$ (the individual rationality (IR) constraint). Second, by the properties of the Nash bargaining solution, $\left(\lambda_{\mathrm{j}}, \mathrm{p}_{\mathrm{j}}\right)$ must maximize the "Nash product", the product of the buyer and seller's payoffs, over all points on the line segment joining $\left(\lambda_{0}, \mathrm{p}_{0}\right)$ and $\left(\lambda_{1}, \mathrm{p}_{1}\right)$ in state $\mathrm{j}, \mathrm{j}=0,1$ (the group incentive compatibility (IC) constraint).

Let us write the buyer and seller's ex post payoffs in states 0,1 as $b_{0}, b_{1}$ and $\mathrm{s}_{0}, \mathrm{~s}_{1}$, respectively. Also let total ex post surplus in the two states be $\mathrm{w}_{0} \equiv \mathrm{b}_{0}+\mathrm{s}_{0}$, $\mathrm{w}_{1} \equiv \mathrm{b}_{1}+\mathrm{s}_{1}$, respectively. Then, from $(2.1)-(2.2)$, we have 


$$
\begin{aligned}
& \mathrm{b}_{0} \equiv \mathrm{v}_{0}\left(\lambda_{0}\right)-\mathrm{p}_{0}=\mathrm{v}-\lambda_{0} \Delta-\mathrm{p}_{0}, \\
& \mathrm{~b}_{1} \equiv \mathrm{v}_{1}\left(\lambda_{1}\right)-\mathrm{p}_{1}=\mathrm{v}-\left(1-\lambda_{1}\right) \Delta-\mathrm{p}_{1},
\end{aligned}
$$

$\mathrm{s}_{0} \equiv \mathrm{p}_{0}-\mathrm{c}_{0}\left(\lambda_{0}\right)=\mathrm{p}_{0}-\mathrm{c}+\lambda_{0} \delta$

$\mathrm{s}_{1} \equiv \mathrm{p}_{1}-\mathrm{c}_{1}\left(\lambda_{1}\right)=\mathrm{p}_{1}-\mathrm{c}+\left(1-\lambda_{1}\right) \delta$

$$
\begin{aligned}
& \mathrm{w}_{0} \equiv \mathrm{v}_{0}\left(\lambda_{0}\right)-\mathrm{c}_{0}\left(\lambda_{0}\right)=\mathrm{v}-\mathrm{c}-\lambda_{0}(\Delta-\delta), \\
& \mathrm{w}_{1} \equiv \mathrm{v}_{1}\left(\lambda_{1}\right)-\mathrm{c}_{1}\left(\lambda_{1}\right)=\mathrm{v}-\mathrm{c}-\left(1-\lambda_{1}\right)(\Delta-\delta) .
\end{aligned}
$$

Hence the IR constraints can be written as

$$
0 \leq \mathrm{b}_{0} \leq \mathrm{w}_{0}, \quad 0 \leq \mathrm{b}_{1} \leq \mathrm{w}_{1}
$$

Before we proceed, it is worth using the IR constraints to say something about the case $\Delta \leq \delta$, which we mentioned briefly in Section 2. In this case the low cost (i.e., cost $\mathrm{c}-\delta$ ) composer is efficient in each state: Shostakovich in state 0 and Bach in state 1 . Consider the contract $\lambda_{0}=1, \lambda_{1}=0, \mathrm{p}_{0}=\mathrm{p}_{1}=\mathrm{c}-\delta$. This contract achieves ex post efficiency and gives all the surplus to the buyer, just satisfying the seller's IR constraint. Any other music (supplied at the common price $\mathrm{c}-\delta$ ) costs the seller strictly more than $\mathrm{c}-\delta$, and so only one point in each state satisfies individual rationality. There is nothing to bargain about: $\left(\lambda_{0}, \mathrm{p}_{0}\right)$ is the Nash bargaining solution in state 0 ; and $\left(\lambda_{1}, \mathrm{p}_{1}\right)$ in state 1 . The contract achieves the first-best.

Let us return to our central case: $\Delta>\delta$. To obtain the IC constraints, it is useful to refer to a diagram. Figure 2 graphs the two parties' payoffs in state 0 .

\section{Figure 2 here}

The contractual frontier consists of all points along the line vector joining the points corresponding to $\left(\lambda_{0}, \mathrm{p}_{0}\right)$ and $\left(\lambda_{1}, \mathrm{p}_{1}\right)$-- the solid arrow in Figure 2. In state 0 the first point is $\left(\mathrm{b}_{0}, \mathrm{~s}_{0}\right)$. Let the second point be $\left(\mathrm{b}_{1}{ }^{\prime}, \mathrm{s}_{1}{ }^{\prime}\right)$, where

$$
\mathrm{b}_{1}^{\prime}=\mathrm{v}-\lambda_{1} \Delta-\mathrm{p}_{1}=\mathrm{b}_{1}+\left(1-2 \lambda_{1}\right) \Delta
$$




$$
\mathrm{s}_{1}^{\prime}=\mathrm{p}_{1}-\mathrm{c}+\lambda_{1} \delta=\mathrm{w}_{1}-\mathrm{b}_{1}-\left(1-2 \lambda_{1}\right) \delta
$$

Note that, except for the case $\lambda_{1}=1 / 2,\left(b_{1}{ }^{\prime}, s_{1}{ }^{\prime}\right) \neq\left(b_{1}, s_{1}\right)$; the reason is that choosing composer $\lambda_{1}$ in state 0 would yield the value-cost combination $\left(v-\lambda_{1} \Delta, \mathrm{c}-\lambda_{1} \delta\right)$, whereas in state 1 (when $\lambda_{1}$ is chosen), it yields $\left(\mathrm{v}-\left(1-\lambda_{1}\right) \Delta, \mathrm{c}-\left(1-\lambda_{1}\right) \delta\right)$.

In Figure 2 we have also drawn the isoquant corresponding to the Nash product passing through $\left(\mathrm{b}_{0}, \mathrm{~s}_{0}\right)$, and its gradient vector -- the dashed arrow. It is clear that, for $\left(\mathrm{b}_{0}, \mathrm{~s}_{0}\right)$ to maximize the Nash product relative to all points on the line vector joining $\left(\mathrm{b}_{0}, \mathrm{~s}_{0}\right)$ to $\left(\mathrm{b}_{1}{ }^{\prime}, \mathrm{s}_{1}{ }^{\prime}\right)$, the gradient vector and this line vector must form an obtuse angle. Since the gradient vector is proportional to $\left(\mathrm{w}_{0}-\mathrm{b}_{0}, \mathrm{~b}_{0}\right)$, we can write the condition as

$$
\left[\mathrm{w}_{0}-\mathrm{b}_{0}\right]\left\{\left[\mathrm{b}_{1}+\left(1-2 \lambda_{1}\right) \Delta\right]-\mathrm{b}_{0}\right\}+\mathrm{b}_{0}\left\{\left[\mathrm{w}_{1}-\mathrm{b}_{1}-\left(1-2 \lambda_{1}\right) \delta\right]-\left[\mathrm{w}_{0}-\mathrm{b}_{0}\right]\right\} \leq 0 .
$$

(3.7) then represents the IC constraint in state 0.

An exactly symmetric argument applies to state 1 . Hence we can obtain the IC constraint in state 1 by substituting $b_{1}$ for $b_{0}, w_{1}$ for $w_{0}$, and $\left(1-\lambda_{0}\right)$ for $\lambda_{1}$ in (3.7).

This yields

$$
\left[\mathrm{w}_{1}-\mathrm{b}_{1}\right]\left\{\left[\mathrm{b}_{0}-\left(1-2 \lambda_{0}\right) \Delta\right]-\mathrm{b}_{1}\right\}+\mathrm{b}_{1}\left\{\left[\mathrm{w}_{0}-\mathrm{b}_{0}+\left(1-2 \lambda_{0}\right) \delta\right]-\left[\mathrm{w}_{1}-\mathrm{b}_{1}\right]\right\} \leq 0 \text {. }
$$

(3.4) and (3.7)-(3.8) together characterize a contract that satisfies the IR and IC constraints in both states, i.e., a feasible contract. ${ }^{15}$

For some purposes it is useful to write the feasibility conditions in terms of the outcomes $\lambda_{0}, \lambda_{1}$ and the prices $\mathrm{p}_{0}, \mathrm{p}_{1}$. Thus we rewrite (3.4), (3.7) and (3.8) as:

\footnotetext{
${ }^{15}$ We noted in Section 2 that in principle no trade could be the outcome in one of the states. However, it is never optimal to have no trade. To see why, note first that, since $\pi_{0} \geq 1 / 2$, it is obviously better for the parties to trade in state 0 than state 1 if they are going to trade in only one state. Suppose that the contract specifies $\left(\lambda_{0}, \mathrm{p}_{0}\right)$ in state 0 and no trade in state 1 . Given that trade occurs only in state 0 , it is clearly optimal for the parties to choose $\lambda_{0}$ efficiently and to allocate all the surplus to the buyer, i.e., $\lambda_{0}=0, \mathrm{p}_{0}=\mathrm{c}$. But then it is easy to show that the contract $\lambda_{0}=\lambda_{1}=0, \mathrm{p}_{0}=\mathrm{p}_{1}=\mathrm{c}$ does better. This contract satisfies (3.4), (3.7) and (3.8) -- assumption (A.1) ensures that the buyer's IR constraint is satisfied in state 1 -- and it yields a higher expected total surplus since there is trade in both states. Incidentally, one could also allow for fractional trade in at least one state, too, but this is never optimal.
} 
$\mathrm{c}-\lambda_{0} \delta \leq \mathrm{p}_{0} \leq \mathrm{v}-\lambda_{0} \Delta, \quad \mathrm{c}-\left(1-\lambda_{1}\right) \delta \leq \mathrm{p}_{1} \leq \mathrm{v}-\left(1-\lambda_{1}\right) \Delta$,

$\left[\mathrm{p}_{0}-\mathrm{c}+\lambda_{0} \delta\right]\left\{\mathrm{p}_{0}-\mathrm{p}_{1}+\left(\lambda_{0}-\lambda_{1}\right) \Delta\right\}+\left[\mathrm{v}-\lambda_{0} \Delta-\mathrm{p}_{0}\right]\left\{\mathrm{p}_{1}-\mathrm{p}_{0}+\left(\lambda_{1}-\lambda_{0}\right) \delta\right\} \leq 0$

(3.11) $\left[\mathrm{p}_{1}-\mathrm{c}+\left(1-\lambda_{1}\right) \delta\right]\left\{\mathrm{p}_{1}-\mathrm{p}_{0}+\left(\lambda_{0}-\lambda_{1}\right) \Delta\right\}$

$$
+\left[\mathrm{v}-\left(1-\lambda_{1}\right) \Delta-\mathrm{p}_{1}\right]\left\{\mathrm{p}_{0}-\mathrm{p}_{1}+\left(\lambda_{1}-\lambda_{0}\right) \delta\right\} \leq 0
$$

The set over which we optimize includes all feasible contracts, together with all convex combinations of such contracts. Formally, a convex combination $\beta C+\mu \mathrm{C}^{\prime}$ of two contracts $C$ and $C^{\prime}$ with weights $\beta$ and $\mu=1-\beta$, respectively, denotes the randomized contract: $\mathrm{C}$ with probability $\beta$ and $\mathrm{C}^{\prime}$ with probability $\mu$, where the objective and verifiable randomization occurs ex post. It may not be actually necessary to conduct a lottery: we will give alternative interpretations later in this section.

We can now define the notions of dominance and optimality. We say that a convex combination of $\mathrm{N}$ individually feasible contracts, $\mathrm{C}_{1}{ }^{\prime}, \ldots, \mathrm{C}_{\mathrm{N}}{ }^{\prime}$, (strictly) dominates a contract $\mathrm{C}$ if the convex combination delivers at least as high a value (a strictly higher value) of expected total surplus, $\mathrm{Ew}=\pi_{0} \mathrm{w}_{0}+\pi_{1} \mathrm{w}_{1}$, and at least as high a value of the buyer's expected return, $E b=\pi_{0} b_{0}+\pi_{1} b_{1}$. An optimal convex combination of $\mathrm{N}$ individually feasible contracts solves the problem: Maximize Ew subject to $\mathrm{Eb} \geq \mathrm{i}$. Obviously, a necessary condition for a feasible contract to be optimal is that it is not strictly dominated.

We will spend a little time exploring the feasibility conditions (3.4), (3.7)-(3.8), or equivalently (3.9)-(3.11). It will simplify the exposition to work with the numerical example from Section 2: $\mathrm{v}=20, \mathrm{c}=10, \Delta=6, \delta=2$. However, all our observations apply more generally, as will be clear from Propositions 1-3 below.

The first point to make is that the first-best cannot be achieved for high values of i. To see this, note that ex post efficiency requires $\lambda_{0}=0, \lambda_{1}=1$. Also, to ensure 
that the buyer invests even when i is high, the buyer must get (almost) all the surplus, i.e., $\mathrm{p}_{0}=\mathrm{p}_{1}=10$. Given that all points on the line segment joining $\left(\lambda_{0}, \mathrm{p}_{0}\right)$ and $\left(\lambda_{1}, \mathrm{p}_{1}\right)$ are permitted, and these points have the common price of 10 , this contract can be interpreted as "any music at a price of 10". However, it is easy to check that this contract violates both (3.10) and (3.11). (For future reference, note that (3.10)-(3.11) become the same condition whenever $\mathrm{p}_{0}=\mathrm{p}_{1}$ and $\lambda_{1}=1-\lambda_{0}$.)

To put it simply, it is impossible both to have ex post efficiency $\left(\lambda_{0}=0\right.$, $\left.\lambda_{1}=1\right)$ and to allocate all the surplus to the buyer, because in equilibrium the Nash product is zero, while everywhere else along the line segment the Nash product is strictly positive. In short, the contract consisting of $\left(\lambda_{0}, \mathrm{p}_{0}\right)=(0,10)$ and $\left(\lambda_{1}, \mathrm{p}_{1}\right)=$ $(1,10)$ violates the IC constraints.

Another way of expressing what we've found is that the contract "any music at a price of 10 " does not yield Bach in state 0 and Shostakovich in state $1 .{ }^{16}$ The problem arises because the buyer is getting too much surplus. We now show that, if we are prepared to allocate a non-trivial fraction of the surplus to the seller, we can find a contract that yields the outcome Bach in state 0 and Shostakovich in state 1 .

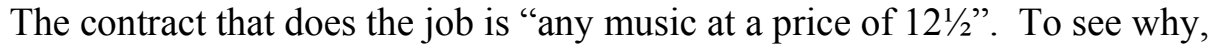
simply substitute $\lambda_{0}=0, \lambda_{1}=1, \mathrm{p}_{0}=\mathrm{p}_{1}=12^{1 / 2}$ into (3.10) (or (3.11)), and check that it is satisfied (with equality). In each state, this contract yields the maximum total ex post surplus of $10\left(\mathrm{w}_{0}=\mathrm{w}_{1}=10\right)$ and provides the buyer with a return of $7 \frac{1}{2}\left(\mathrm{~b}_{0}=\right.$ $\left.\mathrm{b}_{1}=7 \frac{1}{2}\right)$

It is worth observing that (3.10) and (3.11) are also both satisfied (with strict inequality) if $\lambda_{0}=0, \lambda_{1}=1$ and $\mathrm{p}_{0}=\mathrm{p}_{1}>12^{1 / 2}$. In fact, $\mathrm{p}_{0}=\mathrm{p}_{1}=15$ corresponds to the case where the parties write no contract at date 0 and bargain from scratch at date 1.

\footnotetext{
${ }^{16}$ In fact, this contract yields Mozart in both states.
} 
Since we want to provide the buyer with strong investment incentives, we are interested in a contract with low prices and so we concentrate on $\mathrm{p}_{0}=\mathrm{p}_{1}=12^{1 / 2}$.

The reader may wonder whether the buyer's return could be further increased by lowering the price of music below $12^{1 / 2}$. That is, what about a contract that says "any music at $\mathrm{p}$ ", where $\mathrm{p}<12 \frac{1}{2}$, and that yields some $\lambda_{0} \in(0,1 / 2)$ in state 0 and $\lambda_{1}=1-\lambda_{0}$ in state 1 ? Substituting $\mathrm{p}_{0}=\mathrm{p}_{1}=\mathrm{p}$ and $\lambda_{1}=1-\lambda_{0}$ into the equality version of (3.10) (or (3.11)), we obtain (3.12) $\mathrm{p}=12 \frac{1}{2}-3 \lambda_{0}$.

Thus the buyer's return in each state is given by (3.13) $b_{0}=b_{1}=20-6 \lambda_{0}-p=71 / 2-3 \lambda_{0}$, which is less than $7 \frac{1}{2}$ if $\lambda_{0}>0$. In other words, the buyer does less well with the contract "any music at a price of $\mathrm{p}$ " when $\mathrm{p}<12 \frac{1}{2}$, than with the contract "any music at a price of $12^{1 / 2}{ }^{\prime}$. Since "any music at a price of $12^{1 / 2}$ " also delivers higher total ex post surplus, this contract dominates.

An interesting point emerges from the last piece of analysis. As $\lambda_{0} \rightarrow 1 / 2$ from below, $\mathrm{p} \rightarrow 11$ in (3.12). That is, the limiting contract delivers "Mozart at a price of 11". However, when $\lambda_{0}=1 / 2$, Mozart can be obtained at its cost, which equals 9 . In other words, there is a discontinuity. If the buyer wants music close to Mozart (but in the direction of Bach) in state 0, and music close to Mozart (but in the direction of Shostakovich) in state 1 , he must pay close to 11 , whereas if he wants exactly Mozart in both states he need pay only 9 . The source of the discontinuity is that the IC 
constraint becomes vacuous in the limit when there is only one \{music, price pair in the contract (other than "no trade"). ${ }^{17}$

So far, two contracts command our attention. The first is "any music at a price of $12 \frac{1}{2}$ " and the second is "Mozart at a price of 9". Call the first L (for "loose contract") and the second M (for Mozart). Note that, in each state, M yields a total surplus of 8 , which is the return to the buyer. We see that, in each state, $\mathrm{L}$ yields more total surplus than $\mathrm{M}$ (10 vs. 8 ), while $\mathrm{M}$ yields the buyer a higher return than L (8 vs. $71 / 2)$.

Up to now, we have restricted attention to symmetric contracts. But suppose $\pi_{0}$ is close to 1 . Might not an asymmetric contract be better than either L or M?

The answer is yes. For example, consider the specific performance contract "Bach in each state at a price of 10" -- call this B. Then B yields an expected total surplus, and an expected return to the buyer, given respectively by

(3.14) $\mathrm{Ew}=(20-10) \pi_{0}+(14-8) \pi_{1}=6+4 \pi_{0}$,

(3.15) $\mathrm{Eb}=(20-10) \pi_{0}+(14-10) \pi_{1}=4+6 \pi_{0}$.

For $\pi_{0}$ close to 1, Eb exceeds 8 and so B yields a higher expected return to the buyer than either L or M (even though it yields a lower expected total surplus than $\mathrm{L}$ ). In contrast, if $\pi_{0}=1 / 2$, B yields a lower expected return to the buyer than $\mathrm{M}$, and the same total surplus: that is, M dominates B.

Before continuing, we need to deal with an important point. The cost of supplying Bach is 10 in state 0 , but only 8 in state 1 . Might it be possible to have two prices for Bach, a price $\mathrm{p}_{0}=10$, say, which would apply in state 0 , and a lower price,

\footnotetext{
${ }^{17}$ There is no discontinuity if $\lambda_{0} \rightarrow 1 / 2$ from above (i.e., $\lambda_{0}>1 / 2, \lambda_{1}=1-\lambda_{0}, \mathrm{p}_{0}=\mathrm{p}_{1}$ ). However, any feasible contract $\lambda_{0}>1 / 2, \lambda_{1}=1-\lambda_{0}, \mathrm{p}_{0}=\mathrm{p}_{1}$ (i.e., where $\mathrm{p}_{0}=\mathrm{p}_{1}$ is such that IC is satisfied, as well as IR) is dominated by $\lambda_{0}=\lambda_{1}=1 / 2, p_{0}=p_{1}=9$ (i.e., pure Mozart).
} 
$\mathrm{p}_{1} \in[8,10$ ), which would apply in state 1 ? (Recall that in the example in the Introduction, price variability was possible in the loose contract.) The answer is no. In particular, it is easy to check that $\mathrm{p}_{0}=10, \mathrm{p}_{1}<10$ violates $(3.10)-(3.11)$. In rough terms, the reason that $\mathrm{p}_{1}$ cannot be reduced below 10 in state 1 is that unrestricted Nash bargaining in state 1 yields a price of 11, halfway between the buyer's value 14 and the seller's cost 8 , and this price exceeds 10 . In fact, the assumption we made in (A.1), that $\mathrm{v}-\mathrm{c}>\Delta+\delta$, guarantees that a composer does not have two prices in an optimal contract.

Lemma 1. Assume (A.1). If an optimal contract $\left(\lambda_{0}, \mathrm{p}_{0}\right),\left(\lambda_{1}, \mathrm{p}_{1}\right)$ has $\lambda_{0}=\lambda_{1}$, then it must be the case that $\mathrm{p}_{0}=\mathrm{p}_{1}=\max \left\{\mathrm{c}-\lambda_{0} \delta, \mathrm{c}-\left(1-\lambda_{0}\right) \delta\right\}$.

Proof. See Appendix.

Lemma 1 covers the case of general specific performance contracts, for any common value of $\lambda_{0}=\lambda_{1}$. Fortunately, in our analysis of optimality, we do not have to consider these contracts separately from the generalized versions of B and $\mathrm{M}$, namely, "Bach at a price of c" and "Mozart at a price of $c-1 / 2 \delta$ ". To see this, note first that, given $\pi_{0} \geq 1 / 2$, it is never optimal to set $\lambda_{0}=\lambda_{1}>1 / 2$ in a specific performance contract: the contract $\lambda_{0}{ }^{\prime}=\lambda_{1}{ }^{\prime}=1-\lambda_{0}<1 / 2, \mathrm{p}_{0}{ }^{\prime}=\mathrm{p}_{1}{ }^{\prime}=\mathrm{c}-\left(1-\lambda_{0}\right) \delta$ dominates the contract $\lambda_{0}=\lambda_{1}>1 / 2, \mathrm{p}_{0}=\mathrm{p}_{1}=\mathrm{c}-\lambda_{0} \delta$. Assume, therefore, $\lambda_{0}=\lambda_{1}<1 / 2$. The next step is to observe that the contract $\lambda_{0}=\lambda_{1}<1 / 2, \mathrm{p}_{0}=\mathrm{p}_{1}=\mathrm{c}-\lambda_{0} \delta$ is economically equivalent to the convex combination $\left(1-2 \lambda_{0}\right) \mathrm{B}+2 \lambda_{0} \mathrm{M}$, in the sense that the convex combination yields the same expected $\left(\mathrm{w}_{0}, \mathrm{w}_{1}\right)$ and $\left(\mathrm{b}_{0}, \mathrm{~b}_{1}\right)$ vectors. ${ }^{18}$

\footnotetext{
${ }^{18}$ It is not true that a contract $\lambda_{0}=\lambda_{1}>0, \mathrm{p}_{0}=\mathrm{p}_{1}=\mathrm{c}-\lambda_{0} \delta$ is a convex combination of $\mathrm{B}$ and $\mathrm{S}$, where contract S ("Shostakovich at a price of c") has $\lambda_{0}=\lambda_{1}=1$ and $\mathrm{p}_{0}=\mathrm{p}_{1}=\mathrm{c}$. The reason is that contracts $\mathrm{B}$ and $\mathrm{S}$ have a common price $\mathrm{c}$, which strictly exceeds $\mathrm{c}-\lambda_{0} \delta$.
} 
In what follows we will be interested not only in convex combinations of B and $\mathrm{M}$, but also in convex combinations of $\mathrm{L}$ and $\mathrm{B}$, and $\mathrm{L}$ and $\mathrm{M}$. The latter are a little harder to interpret because they are not equivalent to a specific performance contract. The simplest interpretation is that of a lottery. For example, consider a convex combination of $\mathrm{L}$ and $\mathrm{M}$. The parties can sustain this by agreeing at date 0 to choose $\mathrm{L}$ if a particular, verifiable event occurs at date 1 and $\mathrm{M}$ if it does not. A more attractive interpretation is the temporal one mentioned in the Introduction. Imagine that the pianist will perform a series of concerts at date 1, rather than just one, and suppose that the parties bargain about each concert separately. That is, when date 1 arrives, they bargain about the first concert; then after that concert is over they bargain about the second concert, and so on. Then, in our numerical example, the convex combination $(1-\mu) \mathrm{L}+\mu \mathrm{M}$ is equivalent to a date 0 contract stating that Mozart will be performed at a price of 9 for a fraction $\mu$ of the concerts and any music will be performed at a price of $12^{1 / 2}$ for the remainder. ${ }^{19}$

For our numerical example, we may summarize our findings as follows. We have identified three leading contracts: L ("any music at a price of $12 \frac{1}{2}$ ") ; M ("Mozart at a price of 9"); and B ("Bach at a price of 10"). Convex combinations of L, M and B may also be important. However, we have still considered only a very small subset of all possible contracts, in particular, only those with $\lambda_{0}+\lambda_{1}=1$ or $\lambda_{0}=\lambda_{1}$. What about more general contracts, where $\lambda_{0}+\lambda_{1} \neq 1$ and $\lambda_{0} \neq \lambda_{1}$ (e.g.,

\footnotetext{
${ }^{19}$ It is important that the parties cannot bargain about all the concerts simultaneously at date 1 . To rule this out, we must in effect assume that the parties' short-run commitment ability extends over one concert but no further. The reason that simultaneous bargaining won't work is the following. Consider, say, $1 / 2 \mathrm{~L}+1 / 2 \mathrm{M}$. This convex combination yields an average value of $\lambda_{0}$ and $\lambda_{1}$ equal to $1 / 4$ and $3 / 4$ respectively, an average value of $w_{0}$ and $w_{1}$ both equal to 9 , and an average value of $b_{0}$ and $b_{1}$ both equal to $73 / 4$. But it is easy to see that $\lambda_{0}=1 / 4, \lambda_{1}=3 / 4, \mathrm{w}_{0}=\mathrm{w}_{1}=9, \mathrm{~b}_{0}=\mathrm{b}_{1}=73 / 4$ violates (3.7) and (3.8). In other words, it is not possible to sustain $\lambda_{0}=1 / 4, \lambda_{1}=3 / 4, w_{0}=w_{1}=9, b_{0}=b_{1}=73 / 4$ as part of a single Nash bargain. In contrast, it is possible to sustain $\lambda_{0}=0, \lambda_{1}=1, \mathrm{w}_{0}=\mathrm{w}_{1}=10, \mathrm{~b}_{0}=\mathrm{b}_{1}=71 / 2$ as the outcome of one Nash bargain and $\lambda_{0}=\lambda_{1}=1 / 2, \mathrm{w}_{0}=\mathrm{w}_{1}=8, \mathrm{~b}_{0}=\mathrm{b}_{1}=8$ as the outcome of another.
} 
$\left.\lambda_{0}=1 / 4, \lambda_{1}=1 / 2\right)$ ? Can these do better? Fortunately, the answer is no, as Proposition 1 below shows. This means that we can indeed focus on the three contracts L, M, B, and convex combinations of these.

Figure 3 graphs the buyer's expected return and the expected total surplus from the contracts $\mathrm{L}, \mathrm{M}$ and $\mathrm{B}$, for different values of $\pi_{0}$. Since, under $\mathrm{L}$ or $\mathrm{M}$, the buyer's return and the total surplus are independent of the state, the positions of L and $\mathrm{M}$ are fixed across the three figures: only the position of B moves. Figure 3(i) applies to the case $1 / 2 \leq \pi_{0} \leq \pi_{0}{ }^{*}$, where $\pi_{0}{ }^{*}=9 / 14$. Figure 3(ii) applies to the case $\pi_{0}{ }^{*}<\pi_{0}<$ $\pi_{0}{ }^{* *}$, where $\pi_{0}{ }^{* *}=2 / 3$. Figure 3(iii) applies to the case $\pi_{0}{ }^{* *} \leq \pi_{0}<1$.

Figure 3 here

For values of $\pi_{0}$ close to $1 / 2$, Figure 3(i) shows that the frontier consists of two parts. For $i \leq 7 \frac{1}{2}$, the first-best is achieved with the contract L. (For $i \leq 5$, the firstbest can also be achieved with no contract at all, since unrestricted bargaining at date 1 yields the buyer 5.) Ex post, the buyer receives $20-12 \frac{1}{2}=71 \frac{1}{2}$ and total surplus is 10 (the buyer makes an ex ante transfer of $7 \frac{1}{2}-\mathrm{i}$ to reallocate the net surplus to the seller). For $7 \frac{1}{2}<\mathrm{i} \leq 8$, the optimum is achieved by a convex combination of $\mathrm{L}$ and M. Now we are in second-best, since there is ex post inefficiency whenever Mozart is performed (Mozart yields surplus 8 as opposed to 10). Finally, for $\mathrm{i}>8$, the buyer cannot cover his costs and the project will be abandoned (in a first-best world the project is abandoned only if $\mathrm{i}>10)$.

In Figure 3(ii), the first-best is again achieved with the contract $\mathrm{L}$ if $\mathrm{i} \leq 71 \frac{1}{2}$. For $7 \frac{1}{2}<\mathrm{i} \leq 4+6 \pi_{0}$, the optimum is a convex combination of $\mathrm{L}$ and $\mathrm{B}$, whereas for $4+6 \pi_{0} \leq \mathrm{i} \leq 8$, the optimum is a convex combination of B and M (again, the project is abandoned if $\mathrm{i}>8$ ). As we pointed out earlier, this latter convex combination, of $\mathrm{B}$ and $\mathrm{M}$, is equivalent to a specific performance contract of some composer between 
Bach and Mozart: Haydn, say. In Figure 3(iii), the first-best is still achieved with the contract $\mathrm{L}$ if $\mathrm{i} \leq 71 \frac{1}{2}$. In this figure, Mozart is dominated by Bach, and so, provided $71 / 2<\mathrm{i} \leq 4+6 \pi_{0}$, the optimum is a convex combination of $\mathrm{L}$ and $\mathrm{B}$ (the project is abandoned if $\left.\mathrm{i}>4+6 \pi_{0}\right)$.

We have milked our numerical example enough and now it is time to be more general. Fortunately, everything goes through provided we are prepared to make the following assumption:

(A.1') $\mathrm{v}-\mathrm{c} \geq 1 / 2(3 \Delta+\delta)$.

(A.1') is only a slight strengthening of (A.1); it holds as long as the variation in the value and cost of performance is not too great. Note that (A.1') is (just) satisfied in our numerical example.

To state our propositions, we need the generalized version of contract L:

$$
\mathrm{L}=\left\{\left(\lambda_{0}, \mathrm{p}_{0}\right),\left(\lambda_{1}, \mathrm{p}_{1}\right) \mid \lambda_{0}=0, \lambda_{1}=1, \mathrm{p}_{0}=\mathrm{p}_{1}=(\mathrm{c} \Delta+\mathrm{v} \delta) /(\Delta+\delta)\right\}
$$

That is, $\mathrm{L}$ is "any music at a price of $(\mathrm{c} \Delta+\mathrm{v} \delta) /(\Delta+\delta)$ ". Also, to be formal, the generalized versions of contracts $\mathrm{M}$ and $\mathrm{B}$ are:

$$
\mathrm{M}=\left\{\left(\lambda_{0}, \mathrm{p}_{0}\right),\left(\lambda_{1}, \mathrm{p}_{1}\right) \mid \lambda_{0}=\lambda_{1}=1 / 2, \mathrm{p}_{0}=\mathrm{p}_{1}=\mathrm{c}-1 / 2 \delta\right\}
$$$$
\mathrm{B}=\left\{\left(\lambda_{0}, \mathrm{p}_{0}\right),\left(\lambda_{1}, \mathrm{p}_{1}\right) \mid \lambda_{0}=\lambda_{1}=0, \mathrm{p}_{0}=\mathrm{p}_{1}=\mathrm{c}\right\}
$$

That is, $\mathrm{M}$ is "Mozart at a price of $\mathrm{c}-1 / 2 \delta$ ", and B is "Bach at a price of c".

Proposition 1. Assume (A.1'). Then any contract $\left\{\left(\lambda_{0}, \mathrm{p}_{0}\right),\left(\lambda_{1}, \mathrm{p}_{1}\right)\right\}$ is dominated by a convex combination of $\mathrm{L}, \mathrm{M}$ and $\mathrm{B}$.

Proof: See Appendix. ${ }^{20}$

\footnotetext{
${ }^{20}$ Proposition 1 may fail in the absence of (A.1'). Suppose $\mathrm{v}=20, \mathrm{c}=11, \Delta=6, \delta=2$, so that the weaker condition (A.1) holds, but (A.1') doesn't. Consider, e.g., the contract $\left(\lambda_{0}, \mathrm{p}_{0}\right)=(0,11),\left(\lambda_{1}, \mathrm{p}_{1}\right)=$ $(\varepsilon / 6,11-[\varepsilon / 3])$. It is easy to show that this satisfies the IR and IC constraints for small $\varepsilon>0$. Also, for $\pi_{0}$ close to 1 it yields a strictly higher expected return for the buyer than L, M or B. Thus, this contract is not dominated by a convex combination of $\mathrm{L}, \mathrm{M}$ and $\mathrm{B}$.
} 
In Propositions 2 and 3, we characterize an optimal contract for general values of the parameters satisfying (A.1'). There are three critical levels of the buyer's cost of investment i:

(3.19) $\mathrm{i}^{\mathrm{L}}=(\mathrm{v}-\mathrm{c}) \Delta /(\Delta+\delta)$,

(3.20) $\mathrm{i}^{\mathrm{M}}=\mathrm{v}-\mathrm{c}-1 / 2(\Delta-\delta)$,

(3.21) $\mathrm{i}^{\mathrm{B}}=\mathrm{v}-\mathrm{c}-\left(1-\pi_{0}\right) \Delta$.

These are the values of the buyer's expected payoff (gross of investment), Eb, under L, $\mathrm{M}$ and $\mathrm{B}$ respectively. In our numerical example, $\mathrm{i}^{\mathrm{L}}=71 \frac{1}{2}, \mathrm{i}^{\mathrm{M}}=8$ and $\mathrm{i}^{\mathrm{B}}=4+6 \pi_{0}$. In general, $\mathrm{i}^{\mathrm{L}}<\mathrm{i}^{\mathrm{M}}$ if and only if

(3.22) $\mathrm{v}-\mathrm{c}>\left(\Delta^{2}-\delta^{2}\right) / 2 \delta$.

Further, $\mathrm{i}^{\mathrm{L}}<\mathrm{i}^{\mathrm{B}}$ if and only if $\mathrm{v}-\mathrm{c}>\left(1-\pi_{0}\right)(\Delta+\delta) \Delta / \delta$ or, equivalently, (3.23) $\pi_{0}>1-\frac{(\mathrm{v}-\mathrm{c}) \delta}{(\Delta+\delta) \Delta}$

The critical values in (3.19) - (3.23) appear in Propositions 2 and 3 below.

Recall that in our numerical example, $\mathrm{L}$ achieves the first-best if $\mathrm{i} \leq 71 / 2$, irrespective of the value of $\pi_{0}$, i.e., whichever of Figures 3(i)-(iii) pertains.

Proposition 2 generalizes this finding.

Proposition 2. Assume $\mathrm{i} \leq \mathrm{i}^{\mathrm{L}}$. Then $\mathrm{L}$ is optimal, with an ex ante transfer from the seller to the buyer of $i^{\mathrm{L}}-\mathrm{i}$.

The proof is direct. Note that, since the first-best is achieved, Proposition 2 does not require either assumption (A.1) or the stronger assumption (A.1'). Incidentally, if $i \leq 1 / 2(v-c)$, "no contract" is also optimal, with an ex ante transfer of $1 / 2(\mathrm{v}-\mathrm{c})-\mathrm{i}$

We also found in the numerical example that if $i>71 / 2$ the first-best cannot be achieved: there is always some ex post inefficiency. This too generalizes. The three 
cases (i)-(iii) in Proposition 3a correspond to Figures 3(i)-(iii). The auxiliary condition $\mathrm{v}-\mathrm{c}>\left(\Delta^{2}-\delta^{2}\right) / 2 \delta$ is needed to ensure that M yields a strictly higher expected payoff to the buyer than L (if not, M would be dominated by L).

Proposition 3a. Assume $\mathrm{i}>\mathrm{i}^{\mathrm{L}}$ and that (A.1') holds. Suppose $\mathrm{v}-\mathrm{c}>\left(\Delta^{2}-\delta^{2}\right) / 2 \delta$. Then there are three cases:

(i) $\quad 1 / 2 \leq \pi_{0} \leq \pi_{0}^{*} \equiv \frac{\mathrm{v}-\mathrm{c}+\Delta+\delta}{2(\mathrm{v}-\mathrm{c})+\Delta+\delta}$.

For $\mathrm{i} \leq \mathrm{i}^{\mathrm{M}}$, a convex combination of $\mathrm{L}$ and $\mathrm{M}$ is optimal, with weights $\frac{i^{M}-i}{i^{M}-i^{L}}$ and $\frac{i-i^{L}}{i^{M}-i^{L}}$. For $i>i^{M}$, the project is abandoned.

(ii) $\pi_{0}^{*}<\pi_{0}<\pi_{0}^{* *} \equiv \frac{\Delta+\delta}{2 \Delta}$.

For $\mathrm{i}<\mathrm{i}^{\mathrm{B}}$, a convex combination of $\mathrm{L}$ and $\mathrm{B}$ is optimal, with weights $\frac{i^{\mathrm{B}}-\mathrm{i}}{\mathrm{i}^{\mathrm{B}}-\mathrm{i}^{\mathrm{L}}}$ and $\frac{i-i^{L}}{i^{B}-i^{L}}$. For $i \in\left[i^{B}, i^{M}\right]$, a specific performance contract with $\lambda_{\mathrm{j}}=\frac{\mathrm{i}-\mathrm{i}^{\mathrm{B}}}{2\left(\mathrm{i}^{\mathrm{M}}-\mathrm{i}^{\mathrm{B}}\right)}$ and $\mathrm{p}_{\mathrm{j}}=\mathrm{c}-\frac{\delta\left(\mathrm{i}-\mathrm{i}^{\mathrm{B}}\right)}{2\left(\mathrm{i}^{\mathrm{M}}-\mathrm{i}^{\mathrm{B}}\right)}, \mathrm{j}=0,1$, is optimal. For $\mathrm{i}>\mathrm{i}^{\mathrm{M}}$, the project is abandoned.

(iii) $\quad \pi_{0}^{* *} \leq \pi_{0}<1$.

For $\mathrm{i} \leq \mathrm{i}^{\mathrm{B}}$, a convex combination of $\mathrm{L}$ and $\mathrm{B}$ is optimal, with weights $\frac{i^{\mathrm{B}}-\mathrm{i}}{\mathrm{i}^{\mathrm{B}}-\mathrm{i}^{\mathrm{L}}}$ and $\frac{\mathrm{i}-\mathrm{i}^{\mathrm{L}}}{\mathrm{i}^{\mathrm{B}}-\mathrm{i}^{\mathrm{L}}}$. For $\mathrm{i}>\mathrm{i}^{\mathrm{B}}$, the project is abandoned.

We omit a full proof of Proposition 3a because much of it is quite mechanical and closely mimics our earlier discussion of the numerical example. The proof makes use of the fact that the values of the expected total surplus Ew and the buyer's 
expected payoff Eb from a convex combination of $\mathrm{M}$ and $\mathrm{L}$, with weights $\mu: 1-\mu$, are respectively

(3.24) $\mu\{\mathrm{v}-\mathrm{c}-1 / 2(\Delta-\delta)\}+(1-\mu)\{\mathrm{v}-\mathrm{c}\}$,

(3.25) $\mu\{\mathrm{v}-\mathrm{c}-1 / 2(\Delta-\delta)\}+(1-\mu)\{\mathrm{v}-[(\mathrm{c} \Delta+\mathrm{v} \delta) /(\Delta+\delta)]\}$.

So in Ew/Eb space the magnitude of the slope of the frontier joining $\mathrm{L}$ to $\mathrm{M}$ is

$$
\left(-\frac{\partial \mathrm{Ew}}{\partial \mu}\right) /\left(\frac{\partial \mathrm{Eb}}{\partial \mu}\right)=\frac{\Delta-\delta}{[(\mathrm{v}-\mathrm{c}) 2 \delta /(\Delta+\delta)]-(\Delta-\delta)}
$$

Also, from a convex combination of $B$ and $L$, with weights $\beta: 1-\beta$, the values of Ew and $\mathrm{Eb}$ are respectively

$$
\begin{aligned}
& \beta \pi_{0}\{\mathrm{v}-\mathrm{c}\}+\beta\left(1-\pi_{0}\right)\{\mathrm{v}-\mathrm{c}-\Delta+\delta\}+(1-\beta)\{\mathrm{v}-\mathrm{c}\} \\
& \beta \pi_{0}\{\mathrm{v}-\mathrm{c}\}+\beta\left(1-\pi_{0}\right)\{\mathrm{v}-\Delta-\mathrm{c}\}+(1-\beta)\{\mathrm{v}-[(\mathrm{c} \Delta+\mathrm{v} \delta) /(\Delta+\delta)]\}
\end{aligned}
$$

So in $\mathrm{Ew} / \mathrm{Eb}$ space the magnitude of the slope of the frontier joining $\mathrm{L}$ to $\mathrm{B}$ is

$$
\left(-\frac{\partial \mathrm{Ew}}{\partial \beta}\right) /\left(\frac{\partial \mathrm{Eb}}{\partial \beta}\right)=\frac{\left(1-\pi_{0}\right)(\Delta-\delta)}{[(\mathrm{v}-\mathrm{c}) \delta /(\Delta+\delta)]-\left(1-\pi_{0}\right) \Delta}
$$

Comparing (3.26) with (3.29), we find that the frontier joining $\mathrm{L}$ to $\mathrm{M}$ is (in magnitude) less steep than the frontier joining $\mathrm{L}$ to $\mathrm{B}$ if $\pi_{0}$ is less than the lower critical value $\pi_{0}{ }^{*}$ : case (i) in Proposition 3a. The upper critical value, $\pi_{0}{ }^{* *}$, is where B and $\mathrm{M}$ yield the same value of $\mathrm{Eb}$; i.e., $\mathrm{B}$ lies directly above $\mathrm{M}$ in $\mathrm{Ew} / \mathrm{Eb}$ space.

If the auxiliary condition is not satisfied, i.e., if $\mathrm{v}-\mathrm{c} \leq\left(\Delta^{2}-\delta^{2}\right) / 2 \delta$, then $\mathrm{M}$ is dominated by L (for all values of $\pi_{0}$ ), and so is never optimal. For example, suppose $\delta$ is very small. Then $\mathrm{L}$ gives the buyer almost all the surplus (the price $(\mathrm{c} \Delta+\mathrm{v} \delta) /(\Delta+\delta)$ is just above $\mathrm{c})$, as well as being ex post efficient. In contrast, $\mathrm{M}$ is not ex post efficient, so L yields both higher Ew and higher Eb: we need consider only $\mathrm{L}$ and $\mathrm{B}$. 
Proposition $3 \mathrm{~b}$ deals with this possibility. For $\pi_{0}$ below the critical value $\pi_{0}{ }^{* * *}$ given in the proposition, B is also dominated by $\mathrm{L}$ and so is never optimal: case (iv). For $\pi_{0}$ above this value, case (v), convex combinations of L and B are optimal (unless $\mathrm{i}$ is too high, in which case the project is abandoned). Case (v) is akin to case (iii) from Proposition 3a, where Figure 3(iii) pertains.

Proposition 3b. Assume $\mathrm{i}>\mathrm{i}^{\mathrm{L}}$ and that (A.1') holds. Suppose $\mathrm{v}-\mathrm{c} \leq\left(\Delta^{2}-\delta^{2}\right) / 2 \delta$. Then there are two cases:

(iv) $1 / 2 \leq \pi_{0} \leq \pi_{0}^{* * *} \equiv 1-\frac{(\mathrm{v}-\mathrm{c}) \delta}{(\Delta+\delta) \Delta}$

In this case, the project is abandoned.

(v) $\quad \pi_{0}^{* * *}<\pi_{0} \leq 1$.

For $\mathrm{i} \leq \mathrm{i}^{\mathrm{B}}$, a convex combination of $\mathrm{L}$ and $\mathrm{B}$ is optimal, with weights $\frac{i^{\mathrm{B}}-i}{\mathrm{i}^{\mathrm{B}}-\mathrm{i}^{\mathrm{L}}}$ and $\frac{\mathrm{i}-\mathrm{i}^{\mathrm{L}}}{\mathrm{i}^{\mathrm{B}}-\mathrm{i}^{\mathrm{L}}}$. For $\mathrm{i}>\mathrm{i}^{\mathrm{B}}$, the project is abandoned.

Let us sum up our findings. Our numerical example, generalized in Proposition 3a and portrayed in Figures 3(i)-(iii), provides much of the insight. At one extreme, if the buyer's cost of investment, i, is not high, we can achieve the firstbest using the loose contract, L: the horizontal portion of the frontiers in Figures 3 lying to the left of the point L. At the other extreme, if $i$ is very high, the project has to be abandoned because we are to the right of the entire frontier.

For values of $\mathrm{i}$ between these extremes, the project goes ahead but there are ex post inefficiencies. Fortunately, in this second-best region, provided the variation in value $(\Delta)$ and cost $(\delta)$ is not too great (assumption A.1')), we need consider only convex combinations of a pair of contracts, taken from a set of three: the loose 
contract, L, and the two tight contracts, $\mathrm{M}$ and $\mathrm{B}$ (specific performance of Mozart and Bach). Which pair depends on $\pi_{0}$, the probability of state 0 .

This is not the whole story, however. As Proposition 3b shows, for certain parameter configurations, contracts $\mathrm{M}$ and/or B drop out of consideration because they are dominated by contract L. That is, the point L lies "north-east" of either the point $\mathrm{M}$, or the point $\mathrm{B}$, or both. For example, $\mathrm{M}$ is dominated by $\mathrm{L}$ if $\delta$ is small relative to $\Delta$; and $\mathrm{B}$ is dominated by $\mathrm{L}$ if, in addition, $\pi_{0}$ is close to $1 / 2$. When both $\mathrm{M}$ and B are dominated by L, the second-best region disappears (case (iv) of Proposition 3b). This last case is one where the ex post inefficiencies arising from a tight contract are so great that a loose contract is preferred on grounds of both ex ante and ex post efficiency.

We close this section by returning to the question raised in the Introduction about which variables to include in a contract. Propositions 2 and 3 tell us that it is sometimes efficient to specify price and quality, as in the B, M and other specific performance contracts; and it is sometimes efficient to specify price but not quality, as in the L contract. (If $i$ is small enough, "no contract" is optimal, i.e., neither quality nor price needs to be specified.) It is worth saying more about this. As we have noted, the Nash bargaining solution has the property of independence of irrelevant alternatives. An implication is that if the parties know that some aspect of the outcome - the price or nature of the music - should be in a particular range, the contract should say this. That is, flexibility is desirable only to the extent that flexibility is efficiency-enhancing.

In our model there is some genuine uncertainty about the efficient quality -Bach is efficient in state 0 , while Shostakovich is efficient in state 1 -- which is why quality is left open in the L contract. In contrast, there is little uncertainty about cost 
or price. Cost varies between $\mathrm{c}$ and $\mathrm{c}-\delta$, and, by Lemma 1 , given (A.1), this variation is not great enough to call for a variation in price. Thus the parties can safely fix the price. Note that, in the absence of (A.1), price may vary -- and indeed this is precisely what happens in the example in the Introduction.

While in general price will vary as well as quality, there is an asymmetry between the two. Return to our numerical example. Suppose that the set of composers is somewhat bigger, ranging from Albinoni $(\lambda<0)$ to Taverner $(\lambda>1)$. Assume, however, that these additional composers are not efficient: in particular, whereas the cost of Albinoni in state 0 is $10-2 \lambda$, its value is no greater than $20-2 \lambda$. (The value of Taverner is even less than the value of Shostakovich in state 0.) Then it is easy to see that the L contract, "music at price $12 \frac{1}{2}$ ", will still lead to the outcome Bach in state 0 and Shostakovich in state 1 . This is because, in state 0 , the Nash product computed at Albinoni is no greater than $\left(7 \frac{1}{2}-2 \lambda\right)\left(2 \frac{1}{2}+2 \lambda\right)$, and this is less than $75 / 4$, the Nash product at Bach. Hence the parties may not need to worry too much about constraining the choice of music in their contract. However, this is not true of price. Suppose that the parties write a contract that says: "Any music at a price no more than $\overline{\mathrm{p}}$ ”. Then, if $\overline{\mathrm{p}}>12^{1 / 2}$, it is clear that Nash bargaining will lead to a price that exceeds $12^{1 / 2}$. Thus, if the parties want to keep price low to encourage the buyer to invest, they must put the upper bound of $12 \frac{1}{2}$ into the contract. In sum, our model suggests that it is more important for the parties to put constraints on price than on quality. The reason is that the parties' interests over price are diametrically opposed, whereas efficiency considerations will lead to some congruence of preferences over quality. 


\section{Some Foundations for the Contractual Form}

In this section we briefly describe some foundations for the contractual form we have been working with.

As noted in the Introduction we appeal to two assumptions. The first is that, irrespective of any long-run promises entered into ex ante, each party can unilaterally prevent trade ex post by "refusing to cooperate"; moreover, it is impossible for an outsider to verify which party is responsible. The second assumption is that the parties can engage in various forms of commitment: specifically, they can make longrun commitments not to renegotiate their contract; and they can make short-run commitments either to trade or not to trade.

We can provide two justifications for the assumption that each party can bring about no trade by refusing to cooperate. The first is a technological one: in the music example, it is possible for the pianist not to show up, and it is also possible for the impresario to deny the pianist access to the concert hall, and a court cannot distinguish between the two (as in Hart-Moore (1988)).

The second justification is a contractual one. Take the view that any date 0 contract is irretrievably incomplete in the sense that any outcome described is open to conflicting interpretations at date 1 (the quality of the piano playing, the warmth of the hospitality, etc.). Moreover, assume that the seller can always find an interpretation that makes the buyer's value very low (even negative), that the buyer can always find an interpretation that makes the seller's cost very high, and a court cannot resolve any disagreement. ${ }^{21}$ Finally, take the view that, if the parties fail to agree, no trade is the outcome. Then, again, each party can thwart trade by threatening to interpret the contract in a way that is unacceptable to the other party.

\footnotetext{
${ }^{21}$ For discussions of the case where courts fill in the gaps in indefinite contracts, see Ben-Shahar (2004) and Scott (2003).
} 
Let's turn to the second assumption, that parties can make various long-run and short-run commitments. As noted in the Introduction, the assumption that parties can make a long-run commitment not to renegotiate their contract is standard in parts of the literature; however, it is far from uncontroversial. ${ }^{22}$ While parties may want to commit not to renegotiate -- they do in our model -- it is not so easy for them to do so in practice, given that legal regimes typically enforce renegotiated contracts. One justification for the assumption is that there are reputational or psychological impediments to renegotiation. Suppose that we have agreed that you will play Bach for $\$ 15,000$. As the time approaches, you offer to play Shostakovich instead for an extra $\$ 5000$. I will be reluctant to agree to this, even if it is Pareto improving, unless it is obviously costlier for you to play Shostakovich. I am likely to take the view that we already negotiated your fee (and fixed the music), that we could but didn't write a contingent contract, and to adjust the fee now, in the absence of an objective change in circumstances, would be giving in to extortion. (It is also true that you might be reluctant even to offer to play Shostakovich for an extra $\$ 5000$ because you don't want to appear opportunistic.)

Some support for no renegotiation can also be found in the law. Although courts are in principle willing to enforce renegotiated contracts, there are exceptions to this. Specifically, courts may strike down a renegotiated contract if they suspect that there is bad faith or duress, e.g., one party forced the other party to renegotiate by threatening to breach the original contract. ${ }^{23}$ Since bad faith and duress are hard to monitor, the courts may look to see whether renegotiation is justified by a "drastic

\footnotetext{
${ }^{22}$ In fact, in much of our previous work we have adopted the opposite assumption.

${ }^{23}$ See Farnsworth (1999, pp. 276-295).
} 
market shift" or an "unanticipated change in circumstances". ${ }^{24}$ In our model there is no such shift or change, and so our assumption that renegotiation does not occur is consistent with the idea that any renegotiation would fail the courts' (or society's) "smell test". 25

Finally, what about the assumption that each party can make short-run commitments at date 1? This is less standard. One justification for it is the idea that, close to the date of trade, each party can make a statement or verbal promise to the other party to undertake a certain (contingent) action. If the loss of "face" or reputation from breaking this promise quickly is large then the statement will sustain the action, at least for a short period of time. Obviously we do not assume that this kind of commitment can be sustained for a long period of time, e.g., the period from date 0 to date 1 , since then the first-best can be achieved without a contract.

The ability to make short-run commitments, close to the date of trade, has negative and positive consequences. The negative consequence is that each party can credibly threaten not to trade unless he (or she) gets the outcome from the contract he wants. The positive consequence is that each party can commit to uphold any agreement that the parties arrive at through bargaining.

The above assumptions have strong implications. Suppose that the parties set up a mechanism or game at date 0 to be played at date 1 . Let this mechanism specify a (finite) strategy set $\{m\}$ for the buyer, a (finite) strategy set $\{n\}$ for the seller, and an outcome function $(\lambda(m, n), p(m, n), \hat{p}(m, n))$. Here $\lambda(m, n)$ is the composer, $p(m, n)$ is the trade price and $\hat{p}(m, n)$ is the no trade price, given that the buyer chooses strategy

\footnotetext{
${ }^{24}$ See Jolls (1997, pp 228-230).

${ }^{25}$ Bajari-Tadelis (2001) contains an extensive discussion of contracts in the building construction industry. The frequent contract renegotiations (or "change orders") observed in that industry seem to correspond to cases where there is an unanticipated change in circumstances.
} 
$\mathrm{m}$ and the seller chooses strategy $\mathrm{n}$. Recall that each party can unilaterally achieve the no trade outcome by "refusing to cooperate".

Suppose first that the parties anticipate that no trade will occur. Then the parties will play a zero sum game over the choice of $\hat{p}(m, n)$. Let the solution of this game be $\hat{\hat{p}}$ (this is independent of the state of the world), and without loss of generality normalize $\hat{\hat{p}}$ to be zero (through an appropriate choice of transfer at date 0). Then we may conclude that each party's payoff must be non-negative in the overall mechanism since either party can achieve zero by committing not to trade and playing the resulting game over the choice of $\hat{p}(m, n)$.

Next consider the set $\mathrm{T}$ of all composer-trade price pairs $(\lambda, \mathrm{p})$ that can be achieved through the mechanism by particular buyer-seller strategy choices $(m, n)$. That is,

$$
\mathrm{T}=\{(\lambda, p) \mid \lambda=\lambda(m, n), p=p(m, n) \text { for some }(m, n)\}
$$

Let $\overline{\mathrm{T}}$ be the convex hull of this set. (Note that $\mathrm{T}$ and $\overline{\mathrm{T}}$ are independent of the state of the world.) Then in each state of the world the buyer can try to insist on any outcome $(\lambda, p) \in \overline{\mathrm{T}}$ that yields a non-negative payoff for the seller by threatening not to trade unless the seller agrees to choose the (random) strategy $\widetilde{\mathrm{n}}$, where $(\widetilde{\mathrm{m}}, \widetilde{\mathrm{n}})$ yields $(\lambda, \mathrm{p})$ (in return, the buyer agrees to choose $\widetilde{\mathrm{m}}--$ note that we allow the parties to choose correlated strategies). The same is true for the seller. Note that, since each party can make short-run commitments, any pair of strategies $(\widetilde{\mathrm{m}}, \widetilde{\mathrm{n}})$, once agreed upon, can be sustained (it does not have to be a Nash Equilibrium).

Given this structure, the parties in effect bargain over the individually rational elements of $\overline{\mathrm{T}}$. It is not unreasonable to suppose that they adopt the (symmetric) Nash bargaining solution. 
In summary, a contract is a list of $(\lambda, p)$ pairs, together with no trade. Nothing not on the list can occur (this is the no renegotiation assumption). In each state the parties bargain over the individually rational outcomes on the list. But this is precisely the set-up described in Section 2.

\section{Discussion}

It is worth rehearsing the main elements of the paper. We take the view that a contract specifies a list of outcomes. Ex ante, parties commit not to consider outcomes not on the list, i.e., these are ruled out. Ex post, they freely bargain over outcomes on the list (with no trade as the disagreement point), i.e., the contract specifies no mechanism to structure their choice; in this sense outcomes on the list are not ruled in. We have shown that, if relationship-specific investments are not large, the parties will write a loose contract with many outcomes on the list; e.g., in the music example analysed in the paper, the pianist's fee will be fixed but the choice of music will be left open in the range from Bach to Shostakovich, say. However, if relationship-specific investments are large, the parties may need to write a tight contract with few outcomes on the list: for example, the contract might specify that the pianist will play Mozart, even though this is inefficient ex post. Our model also suggests that it is more important for the parties to put constraints on price than on quality.

We have provided some foundations for our view that contracts rule out but do not rule in. The key assumptions are that, irrespective of any long-run promises entered into ex ante, each party can unilaterally and unverifiably prevent trade ex post; that the parties can make a long-run commitment not to renegotiate; and that the parties can make short-run commitments to trade or not to trade. We have shown that 
these assumptions rule out standard mechanisms. It is also worth observing that these assumptions rule out more sophisticated mechanisms involving third parties or lotteries, ${ }^{26}$ as well as mechanisms that rely on "timing". ${ }^{27}$

Some of the assumptions we have made are obviously strong. For example, it would be desirable to relax the no-renegotiation assumption. To this end, it may be useful to distinguish between two kinds of renegotiation: renegotiation in the presence of an objective change in circumstances and renegotiation in the absence of such a change (see the discussion in Section 4). The latter is likely to interfere with investment incentives, while the former may well not. One possibility would be to develop a model in which only the first kind of renegotiation is allowed, e.g., a seller can be paid more if the cost of providing a new service is demonstrably higher but not otherwise.

The assumption of symmetric Nash bargaining could also be usefully relaxed. In principle, it would not be difficult to allow for asymmetric Nash bargaining (the terms of the left-hand side of the IC constraints (3.7)-(3.8) would no longer have equal weight). Moving away from Nash bargaining altogether would be more of a challenge. A very attractive property of the Nash bargaining solution is independence of irrelevant alternatives. As we have seen, this has the implication that the parties never need to include in their contract outcomes that won't occur in equilibrium (and typically the parties won't want to include such outcomes because this makes it harder to satisfy the IC constraints). Not all bargaining solutions have this property. As a result, it may be optimal to include irrelevant outcomes in order to bias the bargaining in an appropriate way.

\footnotetext{
${ }^{26}$ See, e.g., Moore-Repullo (1988), Maskin-Tirole (1999).

${ }^{27}$ See, e.g., Ellman (1999), Lyon-Rasmusen (2004), Watson (2003).
} 
There are some more routine ways in which the analysis could be extended. To mention a few: one could allow for seller investment as well as buyer investment; one could make the buyer's investment continuous (it might affect the magnitude of the buyer's value or the probability that the buyer's value is positive rather than zero); one could allow for more than two states of the world. We also think that it would be interesting to develop the pricing example in the Introduction further (allowing for many cost realizations). As we noted, this model has the feature that inefficiency is caused by (aggregate) cost or supply uncertainty. Some of the early literature on contracts and vertical integration emphasized this idea, ${ }^{28}$ but it has been hard to formalize. The framework described here may be useful for revisiting the issue.

An obvious question to ask is whether there is a role for asset ownership or vertical integration in the type of model described here. The answer would seem to be yes. In our model, tight contracts are sometimes necessary in order to encourage the buyer to invest. If the buyer owns the seller's assets, he has stronger incentives to invest, and so loose contracts may be feasible over a larger parameter range. Note that, in contrast to the standard property rights literature, ${ }^{29}$ ownership is not simply a bargaining chip, since renegotiation will not always lead to ex post efficiency. This suggests that the costs and benefits of ownership may be somewhat different in the current model as compared with the earlier literature, but this remains to be explored.

It is worth saying a few words about the connection between the "loose" contracts studied in this paper and the "incomplete" contracts discussed in much of the recent literature. Both are concerned with observable but not verifiable states of the world, but there are significant differences. As noted in Hart-Moore (1999), the term "incomplete contract" does not have a single meaning. It is used to refer both to

\footnotetext{
${ }^{28}$ See Carlton (1979), Green (1986).

${ }^{29}$ See Grossman-Hart (1986), Hart-Moore (1990).
} 
situations where a contract is "obligationally incomplete" (ambiguous) and to situations where it is "insufficiently state contingent" (this terminology is due to Ayres and Gertner (1992)). With respect to the latter, one cannot tell whether a contract is incomplete just by looking at it. For example, a contract that says that "the seller will supply one widget at a price of 10 " may seem complete, but may be highly incomplete (the parties really wanted the number of widgets and price to depend on the state of the world). Similarly, "no contract" may be complete because the parties wanted no trade; or it may be highly incomplete because the parties wanted to trade but could not write in the relevant contingencies.

In contrast, one can in principle tell whether a contract is "loose" by looking at it: simply see how much flexibility is built in. From this perspective, the contract "the seller will supply one (carefully defined) widget at a price of 10 " is very tight (there is no flexibility or leeway), whereas "no contract" is very loose (since the parties have not closed off any possibilities in the future).

We end on a very speculative note. In our model parties commit not to renegotiate certain things -- e.g., prices -- in order to encourage relationship-specific investments. As a result, they sometimes write "fixed-price" rather than "flexibleprice" contracts. This is obviously reminiscent of aspects of Keynesian thinking. (The rigidities are real rather than nominal.) In future work it might be interesting to explore whether the framework developed here can shed light on the role of quantity rather than price adjustments in the labour and other markets. 


\section{Appendix}

\section{Proof of Lemma 1}

In the contract $C=\left\{\left(\lambda_{0}, \mathrm{p}_{0}\right),\left(\lambda_{1}, \mathrm{p}_{1}\right)\right\}$, let $\lambda$ be the common value of $\lambda_{0}$ and $\lambda_{1}$. In state 0 , the seller's IR constraint from (3.9) is $p_{0} \geq c-\lambda \delta$. We now prove that $p_{1} \geq$ $\mathrm{c}-\lambda \delta$ too. Suppose not; i.e., suppose $\mathrm{p}_{1}<\mathrm{c}-\lambda \delta$. Then, dividing the IC constraint (3.11) by $2\left(\mathrm{p}_{0}-\mathrm{p}_{1}\right)>0$, and rearranging, we obtain

$$
\begin{aligned}
\mathrm{p}_{1} & \geq 1 / 2(\mathrm{v}+\mathrm{c}-\Delta-\delta)+1 / 2 \lambda(\Delta+\delta) \\
& \geq \mathrm{c}+1 / 2 \lambda(\Delta+\delta) \\
& \geq \mathrm{c}
\end{aligned}
$$

where the second inequality follows from (A.1). But $\mathrm{p}_{1} \geq \mathrm{c}$ contradicts our supposition that $\mathrm{p}_{1}<\mathrm{c}-\lambda \delta$. Hence it must be the case that $\mathrm{p}_{1} \geq \mathrm{c}-\lambda \delta$. In sum,

$$
\min \left\{\mathrm{p}_{0}, \mathrm{p}_{1}\right\} \geq \mathrm{c}-\lambda \delta
$$

If we use a symmetric argument in state 1 , interchanging $\mathrm{p}_{0}$ and $\mathrm{p}_{1}$, substituting $1-\lambda$ for $\lambda$, and using the IC constraint (3.10), we obtain

$$
\min \left\{\mathrm{p}_{0}, \mathrm{p}_{1}\right\} \geq \mathrm{c}-(1-\lambda) \delta
$$

Now, if $(*)$ and $(* *)$ were both strict inequalities, or if $\mathrm{p}_{0} \neq \mathrm{p}_{1}$, we could switch to another contract $C^{\prime}$ with the same music, $\lambda_{0}{ }^{\prime}=\lambda_{1}{ }^{\prime}=\lambda$, but with lower prices:

$$
\mathrm{p}_{0}^{\prime}=\mathrm{p}_{1}^{\prime}=\max \{\mathrm{c}-\lambda \delta, \mathrm{c}-(1-\lambda) \delta\}
$$

This new contact $C^{\prime}$ satisfies individual rationality and vacuously satisfies incentive compatibility. Moreover, at least one of the price reductions, $\mathrm{p}_{0}-\mathrm{p}_{0}{ }^{\prime}$ or $\mathrm{p}_{1}-\mathrm{p}_{1}{ }^{\prime}$, is strict, so the buyer's expected return under $\mathrm{C}^{\prime}$ is strictly higher than under $\mathrm{C}$, even though expected total surplus is unchanged. 
This last finding contradicts the assumption in Lemma 1 that $\mathrm{C}$ is optimal. To see why, consider a convex combination of $\mathrm{C}$ ' and "no contract", with weights $\tau$ and $(1-\tau)$, respectively. Since $\left(\lambda_{0}, \lambda_{1}\right) \neq(0,1)$, contracts $\mathrm{C}$ and $\mathrm{C}^{\prime}$ are (equally) inefficient ex post, whereas "no contract" always delivers the efficient choice of music. Thus, for small enough $(1-\tau)>0$, the convex combination of $C^{\prime}$ and "no contract" yields no lower a value of the buyer's expected return than C, but a strictly higher value of expected total surplus.

Q.E.D.

\section{Proof of Proposition 1}

Take any contract $\left\{\left(\lambda_{j}, p_{j}\right) \mid j=0,1\right\}$ for which total surplus is given by

$$
\begin{aligned}
& \mathrm{w}_{0}=\mathrm{v}-\mathrm{c}-\lambda_{0}(\Delta-\delta) \quad \text { in state } 0, \\
& \mathrm{w}_{1}=\mathrm{v}-\mathrm{c}-\left(1-\lambda_{1}\right)(\Delta-\delta) \quad \text { in state } 1,
\end{aligned}
$$

with $\mathrm{Ew}=\pi_{0} \mathrm{w}_{0}+\pi_{1} \mathrm{w}_{1}$; and the buyer's payoff is given by

$$
\begin{aligned}
& \mathrm{b}_{0}=\mathrm{v}-\lambda_{0} \Delta-\mathrm{p}_{0} \quad \text { in state } 0 \\
& \mathrm{~b}_{1}=\mathrm{v}-\left(1-\lambda_{1}\right) \Delta-\mathrm{p}_{1} \quad \text { in state } 1
\end{aligned}
$$

with $\mathrm{Eb}=\pi_{0} \mathrm{~b}_{0}+\pi_{1} \mathrm{~b}_{1}$. For a given value of $\lambda_{\mathrm{j}}, \mathrm{j}=0,1$, individual rationality requires that $0 \leq \mathrm{b}_{\mathrm{j}} \leq \mathrm{w}_{\mathrm{j}}$. Incentive compatibility in state 0 requires that, for a given pair of values $\lambda_{0}$ and $\lambda_{1}$,

$\left(\mathrm{IC}_{0}\right) \quad 0 \geq \mathrm{F}\left(\mathrm{b}_{0}, \mathrm{~b}_{1}\right) \equiv\left[\mathrm{w}_{0}-\mathrm{b}_{0}\right] \mathrm{f}\left(\mathrm{b}_{0}, \mathrm{~b}_{1}\right)+\mathrm{b}_{0}\left\{\left(\lambda_{0}-\lambda_{1}\right)(\Delta-\delta)-\mathrm{f}\left(\mathrm{b}_{0}, \mathrm{~b}_{1}\right)\right\}$, where $f\left(b_{0}, b_{1}\right)$ would be the change in the buyer's payoff in state 0 if the allocation were switched from $\left(\lambda_{0}, \mathrm{p}_{0}\right)$ to $\left(\lambda_{1}, \mathrm{p}_{1}\right)$ :

$$
\mathrm{f}\left(\mathrm{b}_{0}, \mathrm{~b}_{1}\right) \equiv \mathrm{b}_{1}+\left(1-2 \lambda_{1}\right) \Delta-\mathrm{b}_{0} .
$$

(Note that the change in the seller's payoff from this switch would be the term in curly brackets on the right-hand side of $\left(\mathrm{IC}_{0}\right)$.) 
Symmetrically, incentive compatibility in state 1 requires that, for a given pair of values $\lambda_{0}$ and $\lambda_{1}$,

$\left(\mathrm{IC}_{1}\right) \quad 0 \geq \mathrm{G}\left(\mathrm{b}_{0}, \mathrm{~b}_{1}\right) \equiv\left[\mathrm{w}_{1}-\mathrm{b}_{1}\right] \mathrm{g}\left(\mathrm{b}_{0}, \mathrm{~b}_{1}\right)+\mathrm{b}_{1}\left\{\left(\lambda_{0}-\lambda_{1}\right)(\Delta-\delta)-\mathrm{g}\left(\mathrm{b}_{0}, \mathrm{~b}_{1}\right)\right\}$,

where $g\left(b_{0}, b_{1}\right)$ would be the change in the buyer's payoff in state 1 if the allocation were switched from $\left(\lambda_{1}, \mathrm{p}_{1}\right)$ to $\left(\lambda_{0}, \mathrm{p}_{0}\right)$ :

$$
\mathrm{g}\left(\mathrm{b}_{0}, \mathrm{~b}_{1}\right) \equiv \mathrm{b}_{0}-\left(1-2 \lambda_{0}\right) \Delta-\mathrm{b}_{1}
$$

Our strategy for proving Proposition 1 is to show that the contract $\left\{\left(\lambda_{\mathrm{j}}, \mathrm{p}_{\mathrm{j}}\right) \mid \mathrm{j}=0,1\right\}$ is dominated by a convex combination of $\mathrm{L}, \mathrm{B}$ and $\mathrm{M}$, which we will denote with a prime. That is, not only is the expected total surplus higher, $\mathrm{Ew}^{\prime} \geq \mathrm{Ew}$, but so too is the buyer's expected payoff, $\mathrm{Eb}^{\prime} \geq \mathrm{Eb}$.

We divide the proof into three cases, in increasing order of difficulty:

$$
\text { (1) } \lambda_{0}=\lambda_{1} ; \text { (2) } \lambda_{0}>\lambda_{1} ; \text { (3) } \lambda_{0}<\lambda_{1}
$$

\section{Case 1: $\lambda_{0}=\lambda_{1}$}

By Lemma 1, given (A.1) (which is implied by assumption (A.1') made in Proposition 1), if $\lambda_{0}=\lambda_{1}=\lambda$, say, then $\mathrm{p}_{0}=\mathrm{p}_{1}=\max \{\mathrm{c}-\lambda \delta, \mathrm{c}-(1-\lambda) \delta\}=\mathrm{p}$, say.

If $\lambda \leq 1 / 2$, consider the specific performance contract $\left\{\left(\lambda_{j}{ }^{\prime}=\lambda, p_{j}{ }^{\prime}=c-\lambda \delta\right) \mid j=\right.$ $0,1\}$, which is a convex combination of $B$ and $M$. This dominates $\left\{\left(\lambda_{j}, p_{j}\right) \mid j=0,1\right\}$ because, for $\mathrm{j}=0,1$, total surplus is unchanged, $\mathrm{w}_{\mathrm{j}}{ }^{\prime} \equiv \mathrm{w}_{\mathrm{j}}$, and the price is no higher $(\mathrm{c}-\lambda \delta \leq \mathrm{p})$ so the buyer's payoff is no lower, $\mathrm{b}_{\mathrm{j}}^{\prime} \geq \mathrm{b}_{\mathrm{j}}$.

If $\lambda>1 / 2$, consider the specific performance contract $\left\{\left(\lambda_{j}{ }^{\prime}=1-\lambda, p_{j}^{\prime}=\right.\right.$ $\mathrm{c}-(1-\lambda) \delta) \mid \mathrm{j}=0,1\}$, which is also a convex combination of $\mathrm{B}$ and M. Given $\pi_{0} \geq 1 / 2$, expected total surplus rises:

$$
\mathrm{Ew}^{\prime}-\mathrm{Ew}=\left(\pi_{0}-\pi_{1}\right)(2 \lambda-1)(\Delta-\delta) \geq 0
$$


And since the price is no higher $(c-(1-\lambda) \delta \leq p)$, the buyer's expected payoff is no lower, $\mathrm{Eb}^{\prime} \geq \mathrm{Eb}$. Thus $\left\{\left(\lambda_{\mathrm{j}}, \mathrm{p}_{\mathrm{j}}\right) \mid \mathrm{j}=0,1\right\}$ is dominated.

Case 2: $\lambda_{0}>\lambda_{1}$.

If $\lambda_{0} \geq 1 / 2 \geq \lambda_{1}$, then $M$ dominates $\left\{\left(\lambda_{\mathrm{j}}, \mathrm{p}_{\mathrm{j}}\right) \mid \mathrm{j}=0,1\right\}$, because, denoting $\mathrm{M}$ with a prime, total surplus rises in each state:

$$
\begin{aligned}
& \mathrm{w}_{0}{ }^{\prime}=\mathrm{v}-\mathrm{c}-1 / 2(\Delta-\delta) \geq \mathrm{v}-\mathrm{c}-\lambda_{0}(\Delta-\delta)=\mathrm{w}_{0}, \\
& \mathrm{w}_{1}{ }^{\prime}=\mathrm{v}-\mathrm{c}-1 / 2(\Delta-\delta) \geq \mathrm{v}-\mathrm{c}-\left(1-\lambda_{1}\right)(\Delta-\delta)=\mathrm{w}_{1} ;
\end{aligned}
$$

and under $M$ the buyer gets all the surplus, $b_{j}{ }^{\prime} \equiv w_{j}{ }^{\prime}$, for $j=0,1$.

If $1 / 2 \geq \lambda_{0}>\lambda_{1}$, consider the specific performance contract $\left\{\left(\lambda_{j}^{\prime}=\lambda_{0}, p_{j}^{\prime}=\right.\right.$ $\left.\left.\mathrm{c}-\lambda_{0} \delta\right) \mid \mathrm{j}=0,1\right\}$, which is a convex combination of B and M. In state 0 , total surplus is unchanged, $\mathrm{w}_{0}{ }^{\prime}=\mathrm{w}_{0}$, but the buyer gets it all so $\mathrm{b}_{0}{ }^{\prime} \geq \mathrm{b}_{0}$. In state 1 , total surplus is strictly higher:

$$
\mathrm{w}_{1}{ }^{\prime}-\mathrm{w}_{1}=\left(\lambda_{0}-\lambda_{1}\right)(\Delta-\delta)>0 .
$$

The remaining question is whether the buyer's payoff in state 1 is no lower. Suppose this were not true, i.e., suppose $b_{1}{ }^{\prime}<b_{1}$. Then it would have to be the case that $\mathrm{g}\left(\mathrm{b}_{0}, \mathrm{~b}_{1}\right)<0$, given that in state 1 we have in effect switched the allocation from $\left(\lambda_{1}, \mathrm{p}_{1}\right)$ to $\left(\lambda_{0}, \mathrm{p}_{0}\right)$ and then lowered the price from $\mathrm{p}_{0}$ to $\mathrm{c}-\lambda_{0} \delta$. Given $\lambda_{0}>\lambda_{1},\left(\mathrm{IC}_{1}\right)$ would hold only if $\mathrm{w}_{1}$ strictly exceeded $2 \mathrm{~b}_{1}$, which by supposition is strictly more than $2 b_{1}^{\prime}$. But

$$
2 \mathrm{~b}_{1}{ }^{\prime}-\mathrm{w}_{1}=\mathrm{v}-\mathrm{c}-\Delta-\delta+\left(2 \lambda_{0}-\lambda_{1}\right) \Delta+\left(2 \lambda_{0}+\lambda_{1}\right) \delta
$$

which, using (A.1), is non-negative, a contradiction. Thus our supposition must be false. We have shown that $b_{1}{ }^{\prime} \geq b_{1}$, and the specific performance contract $\left\{\left(\lambda_{\mathrm{j}}^{\prime}=\lambda_{0}, \mathrm{p}_{\mathrm{j}}^{\prime}=\mathrm{c}-\lambda_{0} \delta\right) \mid \mathrm{j}=0,1\right\}$ dominates the contract $\left\{\left(\lambda_{\mathrm{j}}, \mathrm{p}_{\mathrm{j}}\right) \mid \mathrm{j}=0,1\right\}$. 
If $\lambda_{0}>\lambda_{1} \geq 1 / 2$, a symmetric argument, reversing the roles of states 0 and 1 , shows that the contract $\left\{\left(\lambda_{\mathrm{j}}, \mathrm{p}_{\mathrm{j}}\right) \mathrm{j}=0,1\right\}$ is dominated by the specific performance contract $\left\{\left(\lambda_{\mathrm{j}}^{\prime}=\lambda_{1}, \mathrm{p}_{\mathrm{j}}^{\prime}=\mathrm{c}-\left(1-\lambda_{1}\right) \delta\right) \mid \mathrm{j}=0,1\right\}$. Moreover, as we argued at the end of

Case 1 , given $\pi_{0} \geq 1 / 2$, this specific performance contract is in turn dominated by the specific performance contract $\left\{\left(\lambda_{j}{ }^{\prime \prime}=1-\lambda_{1}, \mathrm{p}_{\mathrm{j}}{ }^{\prime \prime}=\mathrm{c}-\left(1-\lambda_{1}\right) \delta\right) \mid \mathrm{j}=0,1\right\}$, a convex combination of $\mathrm{B}$ and $\mathrm{M}$.

Case 3: $\lambda_{0}<\lambda_{1}$.

It cannot be the case that $\mathrm{b}_{0}<1 / 2 \mathrm{w}_{0}$ and $\mathrm{b}_{1}<1 / 2 \mathrm{w}_{1}$, because the contract $\left\{\left(\lambda_{\mathrm{j}}, \mathrm{p}_{\mathrm{j}}\right) \mid \mathrm{j}=0,1\right\}$ would be dominated by "no contract" (which yields ex post efficiency and the buyer gets half the total surplus). Suppose $b_{0} \geq 1 / 2 \mathrm{w}_{0}$. Then it must also be the case that $b_{1} \geq 1 / 2 w_{1}$, for otherwise $p_{1}$ could be lowered so that $b_{1}$ equalled $1 / 2 w_{1}$ (thus lowering Eb without affecting Ew) -- this would not violate incentive compatibility because the right-hand side of $\left(\mathrm{IC}_{0}\right)$ would fall and the right-hand side of $\left(\mathrm{IC}_{1}\right)$ would equal $1 / 2 \mathrm{~W}_{1}\left(\lambda_{0}-\lambda_{1}\right)(\Delta-\delta)<0$. By a symmetric argument, if $\mathrm{b}_{1} \geq 1 / 2 \mathrm{~W}_{1}$, then it must also be the case that $b_{0} \geq 1 / 2 w_{0}$. In short, we need only consider values of $b_{0}$ and $b_{1}$ in the range $\left\{1 / 2 \mathrm{w}_{j} \leq \mathrm{b}_{\mathrm{j}} \leq \mathrm{w}_{\mathrm{j}} \mid \mathrm{j}=0,1\right\}$. For convenience, from now on let's refer to this range as "the box". See Figure 4.

Figure 4 here

Within the box, the locus of pairs $\left(\mathrm{b}_{0}, \mathrm{~b}_{1}\right)$ for which $\mathrm{F}\left(\mathrm{b}_{0}, \mathrm{~b}_{1}\right)=0$ slopes strictly up: the line FF in Figure 4. To see why, notice that in the strict interior $\left\{1 / 2 \mathrm{~W}_{j}<b_{j}<\right.$ $\left.\mathrm{w}_{\mathrm{j}} \mathrm{j}=0,1\right\}$, given $\lambda_{0}<\lambda_{1}, \mathrm{~F}\left(\mathrm{~b}_{0}, \mathrm{~b}_{1}\right)=0$ only if

$$
\mathrm{f}\left(\mathrm{b}_{0}, \mathrm{~b}_{1}\right)<0<\left(\lambda_{0}-\lambda_{1}\right)(\Delta-\delta)-\mathrm{f}\left(\mathrm{b}_{0}, \mathrm{~b}_{1}\right)
$$

But then, in the strict interior along FF, $F\left(b_{0}, b_{1}\right)$ strictly increases with $b_{0}$ and strictly decreases with $b_{1}$ : 


$$
\begin{aligned}
& \frac{\partial \mathrm{F}}{\partial \mathrm{b}_{0}}=\left(\lambda_{0}-\lambda_{1}\right)(\Delta-\delta)-2 \mathrm{f}\left(\mathrm{b}_{0}, \mathrm{~b}_{1}\right)+2 \mathrm{~b}_{0}-\mathrm{w}_{0}>0, \\
& \frac{\partial \mathrm{F}}{\partial \mathrm{b}_{1}}=\mathrm{w}_{0}-2 \mathrm{~b}_{0}<0 .
\end{aligned}
$$

Symmetrically, within the box, the locus of pairs $\left(b_{0}, b_{1}\right)$ for which $G\left(b_{0}, b_{1}\right)=0$ also slopes strictly up: the line GG. In particular, in the strict interior, $G\left(b_{0}, b_{1}\right)=0$ only if

$$
\mathrm{g}\left(\mathrm{b}_{0}, \mathrm{~b}_{1}\right)<0<\left(\lambda_{0}-\lambda_{1}\right)(\Delta-\delta)-\mathrm{g}\left(\mathrm{b}_{0}, \mathrm{~b}_{1}\right)
$$

so that in the strict interior along $\mathrm{GG}, \mathrm{G}\left(\mathrm{b}_{0}, \mathrm{~b}_{1}\right)$ strictly decreases with $\mathrm{b}_{0}$ and strictly increases with $b_{1}$ :

$$
\begin{aligned}
& \frac{\partial \mathrm{G}}{\partial \mathrm{b}_{0}}=\mathrm{w}_{1}-2 \mathrm{~b}_{1}<0, \\
& \frac{\partial \mathrm{G}}{\partial \mathrm{b}_{1}}=\left(\lambda_{0}-\lambda_{1}\right)(\Delta-\delta)-2 \mathrm{~g}\left(\mathrm{~b}_{0}, \mathrm{~b}_{1}\right)+2 \mathrm{~b}_{1}-\mathrm{w}_{1}>0 .
\end{aligned}
$$

Moreover, it is straightforward to show that, if FF and GG intersect, FF is strictly steeper than GG at the point of intersection:

$$
\left(\frac{\partial \mathrm{F}}{\partial \mathrm{b}_{0}}\right) /\left(-\frac{\partial \mathrm{F}}{\partial \mathrm{b}_{1}}\right)>\left(-\frac{\partial \mathrm{G}}{\partial \mathrm{b}_{0}}\right) /\left(\frac{\partial \mathrm{G}}{\partial \mathrm{b}_{1}}\right) .
$$

Thus they intersect at most once. The shaded area in Figure 4 comprises the pairs $\left(b_{0}, b_{1}\right)$ for which $F\left(b_{0}, b_{1}\right) \leq 0$ and $G\left(b_{0}, b_{1}\right) \leq 0$, i.e., the pairs $\left(b_{0}, b_{1}\right)$ that satisfy incentive compatibility for given values of $\lambda_{0}$ and $\lambda_{1}$. Note that the shaded area is not empty, since $\mathrm{F}\left(1 \frac{1}{2} \mathrm{w}_{0}, 1 / 2 \mathrm{w}_{1}\right)<0$ and $\mathrm{G}\left(1 / 2 \mathrm{w}_{0}, 1 / 2 \mathrm{w}_{1}\right)<0$.

Without loss of generality, suppose $\lambda_{0}+\lambda_{1} \leq 1$. (If $\lambda_{0}+\lambda_{1}>1$, reverse the roles of states 0 and 1 in what follows -- inter alia, replacing $\lambda_{j}$ by $1-\lambda_{j}$, $\mathrm{j}=0,1$. This can be done legitimately, because we will not use the assumption $\pi_{0} \geq 1 / 2$ in the proof for Case 3.) 
Consider a contract comprising the convex combination $\left(1-\lambda_{0}-\lambda_{1}\right) \mathrm{B}+2 \lambda_{0} \mathrm{M}$ $+\left(\lambda_{1}-\lambda_{0}\right) \mathrm{L}$, which we denote with a prime. This yields the same vector of average total surplus as the contract $\left\{\left(\lambda_{\mathrm{j}}, \mathrm{p}_{\mathrm{j}}\right) \mid \mathrm{j}=0,1\right\}$ :

$$
\begin{aligned}
\mathrm{w}_{0}{ }^{\prime} & =\left(1-\lambda_{0}-\lambda_{1}\right)[\mathrm{v}-\mathrm{c}]+2 \lambda_{0}[\mathrm{v}-\mathrm{c}-1 / 2(\Delta-\delta)]+\left(\lambda_{1}-\lambda_{0}\right)[\mathrm{v}-\mathrm{c}] \\
& =\mathrm{v}-\mathrm{c}-\lambda_{0}(\Delta-\delta)=\mathrm{w}_{0}, \\
\mathrm{w}_{1}{ }^{\prime} & =\left(1-\lambda_{0}-\lambda_{1}\right)[\mathrm{v}-\mathrm{c}-(\Delta-\delta)]+2 \lambda_{0}[\mathrm{v}-\mathrm{c}-1 / 2(\Delta-\delta)]+\left(\lambda_{1}-\lambda_{0}\right)[\mathrm{v}-\mathrm{c}] \\
& =\mathrm{v}-\mathrm{c}-\left(1-\lambda_{1}\right)(\Delta-\delta)=\mathrm{w}_{1} .
\end{aligned}
$$

The buyer's average payoffs from the convex combination are

$$
\begin{aligned}
& \mathrm{b}_{0}{ }^{\prime}=\mathrm{v}-\mathrm{c}-\lambda_{0}(\Delta-\delta)-\left(\lambda_{1}-\lambda_{0}\right)(\mathrm{v}-\mathrm{c}) \frac{\delta}{\Delta+\delta}, \\
& \mathrm{b}_{1}{ }^{\prime}=\mathrm{v}-\mathrm{c}-\left(1-\lambda_{1}\right) \Delta+\lambda_{0} \delta-\left(\lambda_{1}-\lambda_{0}\right)(\mathrm{v}-\mathrm{c}) \frac{\delta}{\Delta+\delta}
\end{aligned}
$$

Note that $b_{0}{ }^{\prime}-b_{1}{ }^{\prime}=\left(1-\lambda_{0}-\lambda_{1}\right) \Delta$.

Our aim is to show that $\left(\mathrm{b}_{0}{ }^{\prime}, \mathrm{b}_{1}{ }^{\prime}\right)$ vector dominates (i.e. lies "north-east" of) all points in the shaded area in Figure 4. Note that

$$
\mathrm{F}\left(\mathrm{b}_{0}{ }^{\prime}, \mathrm{b}_{1}{ }^{\prime}\right)=\left(\lambda_{1}-\lambda_{0}\right) \delta \Phi
$$

where $\Phi \equiv\left(1-\lambda_{1}+\lambda_{0}\right)(\mathrm{v}-\mathrm{c})-\lambda_{0}(\Delta-\delta)$

$$
\begin{aligned}
& \geq\left(1-\lambda_{1}+\lambda_{0}\right)(\Delta+\delta)-\lambda_{0}(\Delta-\delta) \quad \text { (using (A.1)) } \\
& =\left(1-\lambda_{1}\right) \Delta+\left(1-\lambda_{1}+2 \lambda_{0}\right) \delta \\
& >0
\end{aligned}
$$

That is, $\left(\mathrm{b}_{0}^{\prime}, \mathrm{b}_{1}{ }^{\prime}\right)$ lies below the line FF. Also

$$
\mathrm{G}\left(\mathrm{b}_{0}{ }^{\prime}, \mathrm{b}_{1}{ }^{\prime}\right)=\left(\lambda_{1}-\lambda_{0}\right) \delta \Gamma
$$

where $\Gamma \equiv\left(1-\lambda_{1}+\lambda_{0}\right)(\mathrm{v}-\mathrm{c})-\left(1-\lambda_{1}\right) 2 \Delta+\lambda_{0}(\Delta+\delta)$.

Thus if 
$(* * *) \quad \mathrm{v}-\mathrm{c} \geq \frac{\left(1-\lambda_{1}\right) 2 \Delta-\lambda_{0}(\Delta+\delta)}{1-\lambda_{1}+\lambda_{0}}$

we have $G\left(b_{0}^{\prime}, b_{1}{ }^{\prime}\right) \geq 0$, and $\left(b_{0}^{\prime}, b_{1}^{\prime}\right)$ lies above the line GG. Given $(* * *)$, then, we have proved that $\left(\mathrm{b}_{0}{ }^{\prime}, \mathrm{b}_{1}{ }^{\prime}\right)$ vector dominates all points in the shaded area. This means that $b_{0}{ }^{\prime} \geq b_{0}$ and $b_{1}^{\prime} \geq b_{1}$, and we are done.

It remains to deal with the case where $(* * *)$ does not hold. Our method of proving that, even in this case, $\left(\mathrm{b}_{0}^{\prime}, \mathrm{b}_{1}^{\prime}\right)$ vector dominates all points in the shaded area is to find the value $y>0$ for which $G\left(b_{0}{ }^{\prime}-y, b_{1}{ }^{\prime}\right)=0$ and to show that $F\left(b_{0}{ }^{\prime}-y, b_{1}{ }^{\prime}\right)>0$. See Figure 4. (Incidentally, towards the end of this final part of the argument, we will make use of our assumption (A.1'): here is the only step in the proof of Proposition 1 where we actually need (A.1'), rather than the weaker assumption (A.1).)

Now $\mathrm{F}\left(\mathrm{b}_{0}{ }^{\prime}-\mathrm{y}, \mathrm{b}_{1}{ }^{\prime}\right)$ can be expressed

$$
2 \mathrm{y}^{2}-\mathrm{y}(\mathrm{A}+\mathrm{a})+\left(\lambda_{1}-\lambda_{0}\right) \delta \Phi
$$

where $\mathrm{a} \equiv\left(1 / 2-\lambda_{0}\right)(\Delta+\delta), \quad$ and

$$
\begin{aligned}
\mathrm{A} & \equiv(\mathrm{v}-\mathrm{c})\left[1-\left(\lambda_{1}-\lambda_{0}\right) \frac{2 \delta}{\Delta+\delta}\right]-\left(1 / 2-\lambda_{1}\right)(\Delta+\delta)-\lambda_{0}(\Delta-\delta) \\
& \left.\geq(\Delta+\delta)\left[1-\left(\lambda_{1}-\lambda_{0}\right) \frac{2 \delta}{\Delta+\delta}\right]-\left(1 / 2-\lambda_{1}\right)(\Delta+\delta)-\lambda_{0}(\Delta-\delta) \quad \text { (using (A.1) }\right) \\
& =1 / 2(\Delta+\delta)+\left(\lambda_{1}-\lambda_{0}\right)(\Delta-\delta)+2 \lambda_{0} \delta \\
& >0
\end{aligned}
$$

$\mathrm{G}\left(\mathrm{b}_{0}{ }^{\prime}-\mathrm{y}, \mathrm{b}_{1}{ }^{\prime}\right)$ can be written

$$
\mathrm{y}(\mathrm{A}-\mathrm{a})+\left(\lambda_{1}-\lambda_{0}\right) \delta \Gamma
$$

Note that $\mathrm{A}-\mathrm{a}=(\mathrm{v}-\mathrm{c})\left[1-\left(\lambda_{1}-\lambda_{0}\right) \frac{2 \delta}{\Delta+\delta}\right]-\left(1-\lambda_{1}\right)(\Delta+\delta)+2 \lambda_{0} \delta$ 


$$
\begin{aligned}
& \geq(\Delta+\delta)\left[1-\left(\lambda_{1}-\lambda_{0}\right) \frac{2 \delta}{\Delta+\delta}\right]-\left(1-\lambda_{1}\right)(\Delta+\delta)+2 \lambda_{0} \delta(\operatorname{using}(\mathrm{A} .1)) \\
& =\lambda_{1}(\Delta-\delta)+4 \lambda_{0} \delta \\
& >0
\end{aligned}
$$

Hence, given that $(* * *)$ does not hold, so that $\Gamma<0$, the value of $\mathrm{y}$ which solves $\mathrm{G}\left(\mathrm{b}_{0}^{\prime}-\mathrm{y}, \mathrm{b}_{1}^{\prime}\right)=0$ satisfies $\mathrm{y}>0$

For this value of $y$, the sign of $F\left(b_{0}^{\prime}-y, b_{1}^{\prime}\right)$ is the same as the sign of

$$
\begin{aligned}
& (A-a) F\left(b_{0}^{\prime}-y, b_{1}^{\prime}\right)+(A+a) G\left(b_{0}^{\prime}-y, b_{1}{ }^{\prime}\right) \\
= & 2(A-a) y^{2}+\left(\lambda_{1}-\lambda_{0}\right) \delta[A(\Phi+\Gamma)-a(\Phi-\Gamma)] .
\end{aligned}
$$

Hence a sufficient condition for $F\left(b_{0}{ }^{\prime}-y, b_{1}{ }^{\prime}\right)>0$ is that

$$
\begin{aligned}
0<\mathrm{A}(\Phi+\Gamma)-\mathrm{a}(\Phi-\Gamma) & \\
=\mathrm{A} & {\left[2\left(1-\lambda_{1}+\lambda_{0}\right)\left(\mathrm{v}-\mathrm{c}-\frac{3 \Delta+\delta}{2}\right)+\left(1-\lambda_{1}+3 \lambda_{0}\right)(\Delta+\delta)\right] } \\
& -\mathrm{a}\left[2\left(1-\lambda_{0}-\lambda_{1}\right) \Delta\right] .
\end{aligned}
$$

In turn, a sufficient condition for this, given (A.1'), is that

$$
\left(1-\lambda_{1}+3 \lambda_{0}\right) \mathrm{A}-\left(1-\lambda_{0}-\lambda_{1}\right)\left(1-2 \lambda_{0}\right) \Delta>0 .
$$

Again using (A.1'),

$$
\begin{aligned}
& \left(1-\lambda_{1}+3 \lambda_{0}\right) \mathrm{A}-\left(1-\lambda_{0}-\lambda_{1}\right)\left(1-2 \lambda_{0}\right) \Delta \\
& \geq\left(1-\lambda_{1}+3 \lambda_{0}\right)\left\{\frac{3 \Delta+\delta}{2}\left[1-\left(\lambda_{1}-\lambda_{0}\right) \frac{2 \delta}{\Delta+\delta}\right]-\left(\frac{1}{2}-\lambda_{1}\right)(\Delta+\delta)-\lambda_{0}(\Delta-\delta)\right\} \\
& -\left(1-\lambda_{0}-\lambda_{1}\right)\left(1-2 \lambda_{0}\right) \Delta \\
& =2 \lambda_{0}\left[\left(3-\lambda_{0}-\lambda_{1}\right) \Delta+\left(1-\lambda_{1}+3 \lambda_{0}\right) \delta\right]+\left(1-\lambda_{1}+3 \lambda_{0}\right)\left(\lambda_{1}-\lambda_{0}\right)\left(1-\frac{2 \delta}{\Delta+\delta}\right) \Delta \\
& >0 .
\end{aligned}
$$

The proof of Proposition 1 is complete.

Q.E.D. 


\section{References}

Aghion, P., M. Dewatripont, and P. Rey (1994), "Renegotiation Design with Unverifiable Information," Econometrica 62: 257-82.

Allen, Franklin, and Douglas Gale (1992), "Measurement Distortion and Missing Contingencies in Optimal Contracts," Economic Theory 2: 1-26

Ayres, I., and R. Gertner (1992), "Strategic Contractual Inefficiency and the Optimal Choice of Legal Rules," The Yale Law Journal 101: 719-73.

Bajari, Patrick, and Steven Tadelis (2001), "Incentives versus Transaction Costs: A Theory of Procurement Contracts," The Rand Journal of Economics 32: 387-407.

Baker, George, Robert Gibbons, and Kevin J. Murphy (1994), "Subjective Performance Measures in Optimal Incentive Contracts," Quarterly Journal of Economics 109: 1125-56.

Ben-Shahar, Omri (2004), "Agreeing to Disagree: Filling Gaps in Deliberately Incomplete Contracts," Michigan Law and Economics Research Paper No. 04-002, January.

Bernheim, B. Douglas, and Michael D. Whinston (1998), "Incomplete Contracts and Strategic Ambiguity,” American Economic Review 88: 902-32.

Binmore, Ken, A. Rubinstein, and A. Wolinsky (1986), "The Nash Bargaining Solution in Economic Modelling," The Rand Journal of Economics 17: 176-88.

Boot, Arnoud W. A., Stuart I. Greenbaum, and Anjan V. Thakor (1993), "Reputation and Discretion in Financial Contracting," American Economic Review 83: 1165-83.

Carlton, Dennis (1979), "Vertical Integration in Competitive Markets Under Uncertainty,” Journal of Industrial Economics 27: 189-209.

Che, Y.-K., and D. Hausch (1999), "Cooperative Investments and the Value of Contracting," American Economic Review 89: 125-47.

Chung, Tai-Yeong (1991), "Incomplete Contracts, Specific Investments, and Risk Sharing," The Review of Economic Studies 58: 1031-42.

Dewatripont, M. (1989), "Renegotiation and Information Revelation over Time: The Case of Optimal Labor Contracts," Quarterly Journal of Economics 104: 589-619.

Ellman, Matthew B. (1999), "Essays on the Economics of Organizations," dissertation, Harvard University.

Farnsworth, E. Allan (1999), Contracts, New York: Aspen Law \& Business. 
Green, Jerry (1986), "Vertical Integration and Assurance of Markets," in New Developments in the Analysis of Market Structure, eds. F. G. Mathewson and J. E. Stiglitz, Cambridge, MA: MIT Press.

Grossman, Sanford, and Oliver Hart (1986), "The Costs and Benefits of Ownership: A Theory of Vertical and Lateral Integration" Journal of Political Economy 94: 691719.

Grout, P. A. (1984), "Investment and Wages in the Absence of Binding Contracts: A Nash Bargaining Approach,” Econometrica 52: 449-60.

Harstad, Bard (2003), "Organizing Cooperation: Bargaining, Voting and Control," dissertation, Stockholm University.

Hart, Oliver, and John Moore (1988), "Incomplete Contracts and Renegotiation," Econometrica 56: 755-85.

and (1990), "Property Rights and the Nature of the Firm," Journal of Political Economy 98: 1119-58. and (1999), "Foundations of Incomplete Contracts," The Review of Economic Studies 66(1): 115-38. and J. Tirole (1988), "Contract Renegotiation and Coasian Dynamics," The Review of Economic Studies 55: 509-40.

Holmstrom, B. (1979), "Moral Hazard and Observability,” Bell Journal of Economics 10: 74-91.

Jolls, Christine (1997), "Contracts as Bilateral Commitments: A New Perspective on Contract Modification," Journal of Legal Studies 26: 203-37.

Klein, B., R. Crawford, and A. Alchian (1978), "Vertical Integration, Appropriable Rents, and the Competitive Contracting Process," Journal of Law and Economics 21: 197-326.

Laffont, Jean-Jacques, and Jean Tirole (1990), “Adverse Selection and Renegotiation in Procurement," The Review of Economic Studies 57: 597-626.

Lyon, Thomas P., and E. Rasmusen, "Buyer-Option Contracts, Renegotiation, and the Hold-Up Problem," forthcoming, Journal of Law, Economics and Organization 20,1 (Spring 2004).

MacLeod, W. Bentley, and James M. Malcomson (1989), "Implicit Contracts, Incentive Compatibility and Involuntary Unemployment," Econometrica 57: 447-80. and (1993), "Investments, Holdup, and the Form of Market Contracts," American Economic Review 83: 811-37. 
Maskin, Eric (1999), "Nash Equilibrium and Welfare Optimality," The Review of Economic Studies 66: 23-38.

and John Moore (1999), "Implementation and Renegotiation," The

Review of Economic Studies 66: 39-56.

and Jean Tirole (1999), "Unforeseen Contingencies and Incomplete

Contracts," The Review of Economic Studies 66: 83-114.

Mirrlees, James (1971), "An Exploration in the Theory of Optimum Income Taxation," The Review of Economic Studies 38: 175-208.

(1999), "The Theory of Moral Hazard and Unobservable Behaviour: Part

I," The Review of Economic Studies 66: 3-21.

Moore, John, and Rafael Repullo (1988), "Subgame Perfect Implementation," Econometrica 56: 1191-1220.

Mussa, Michael, and Sherwin Rosen (1978), "Monopoly and Product Quality," Journal of Economic Theory 18: 301-17.

Myerson, Roger (1979), "Incentive Compatibility and the Bargaining Problem," Econometrica 47: 61-74.

and M. Satterthwaite (1983), "Efficient Mechanisms for Bilateral Trading," Journal of Economic Theory 29: 256-81.

Nash, John F., Jr. (1950), “The Bargaining Problem,” Econometrica 18: 155-62.

Noldeke, G. and K. Schmidt (1995), "Option Contracts and Renegotiation: A

Solution to the Hold-Up Problem," The Rand Journal of Economics 26: 163-179.

Reiche, Soenje (2003), “Ambivalent Investment and the Hold-Up Problem,” mimeo, University of Pennsylvania.

Rogerson, William (1992), "Contractual Solutions to the Hold-Up Problem," The Review of Economic Studies 59: 777-93.

Roth, Al (1979), Axiomatic Models of Bargaining. Berlin: Springer-Verlag.

Scott, Robert E. (2003), "A Theory of Self-Enforcing Indefinite Agreements," Columbia Law Review 103: 1641-99.

Segal, Ilya (1999), "Complexity and Renegotiation: A Foundation for Incomplete Contracts," The Review of Economic Studies 66: 57-82.

and Michael Whinston (2002), “The Mirrlees Approach to Mechanism Design with Renegotiation (with Applications to Hold-Up and Risk Sharing)," Econometrica 70: 1-45. 
Shavell, Steven (2004), Foundations of Economic Analysis of Law. Cambridge MA: Belknap Press.

Spier, Kathryn E. (1992), "Incomplete Contracts and Signalling," The Rand Journal of Economics 23: 432-43.

Watson, Joel (2003), "Contract, Mechanism Design, and Technological Detail," mimeo, University of California, San Diego.

Williamson, Oliver (1975), Markets and Hierarchies: Analysis and Antitrust Implications. New York: Free Press. 


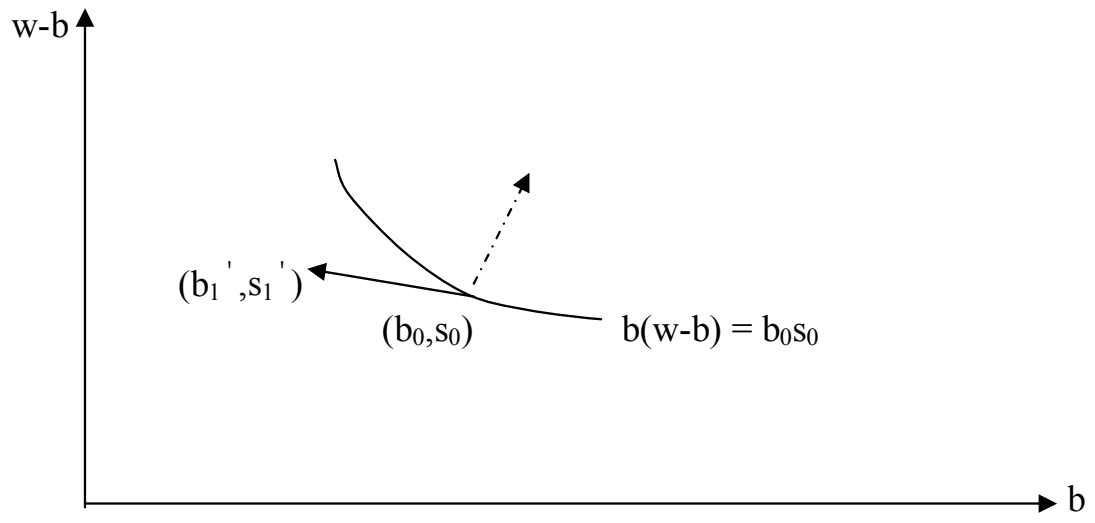

Figure 2 


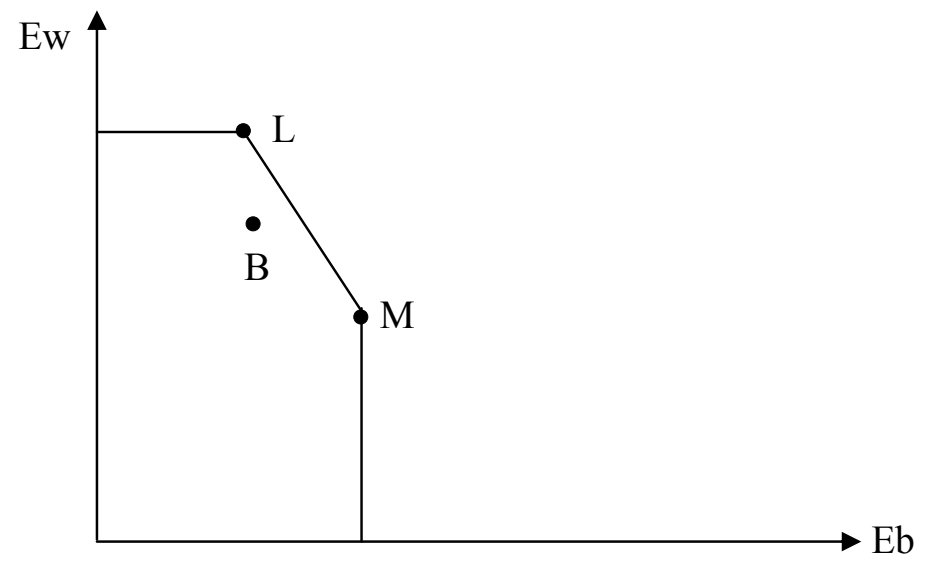

Figure 3(i): $\pi_{0} \leq \pi_{0}^{*}$

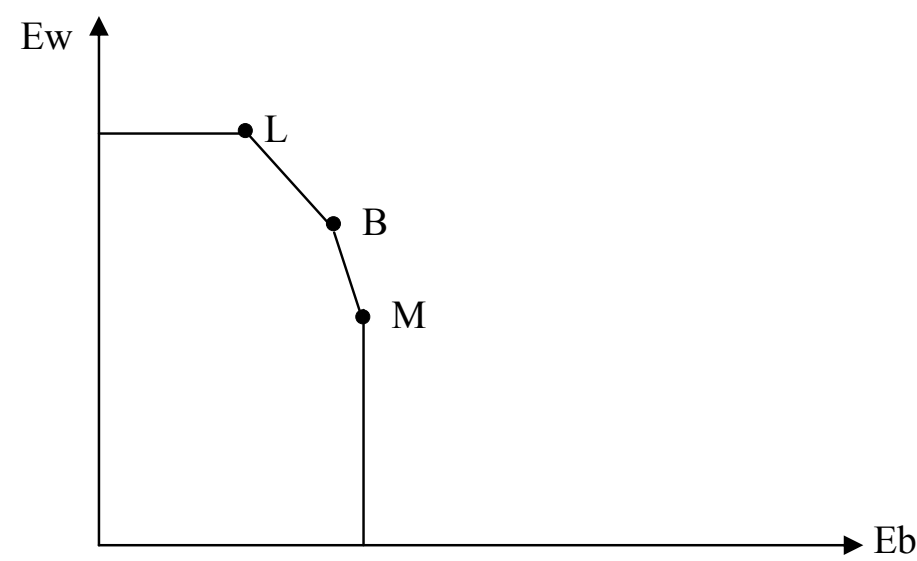

Figure 3(ii): $\pi_{0}^{*}<\pi_{0}<\pi_{0}^{* *}$

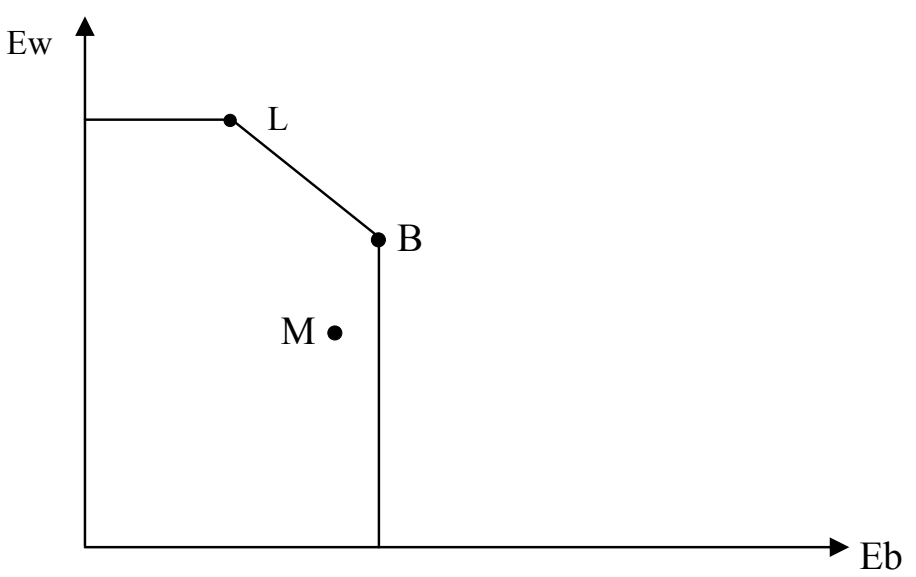

Figure 3(iii): $\quad \pi_{0} \geq \pi_{0}^{* *}$ 


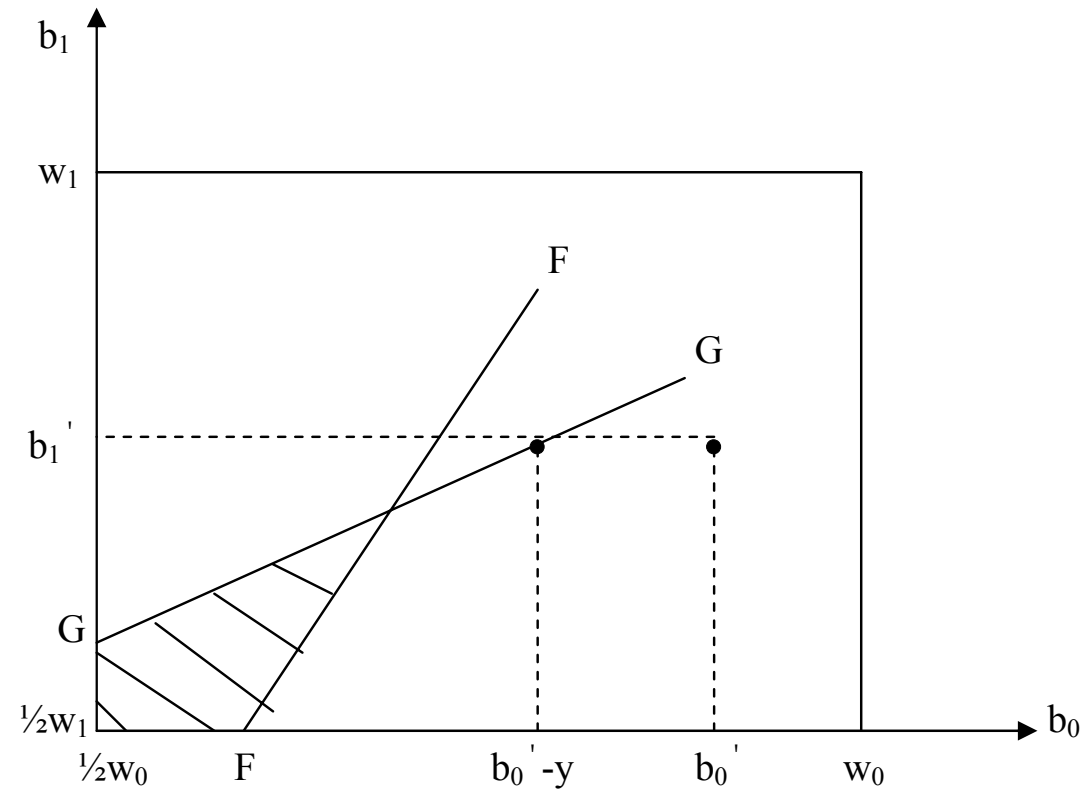

Figure 4: Proof of Proposition 1, Case 3 